\title{
CONTROL OF MESENCHYMAL STEM CELL PHENOTYPE AND DIFFERENTIATION DEPENDING ON CELL ADHESION MECHANISM
}

\author{
J. Kang ${ }^{1,3,}$, H-M. Park ${ }^{2, \S}$, Y-W. Kim ${ }^{4}$, Y.H. Kim ${ }^{5}$, S. Varghese ${ }^{6}$, H.K. Seok ${ }^{1}$, Y-G. Kim ${ }^{4}$ and S-H. Kim ${ }^{1,3, *}$ \\ ${ }^{1}$ Center for Biomaterials, Biomedical Research Institute, Korea Institute of Science and Technology, Seoul, \\ Republic of Korea. \\ ${ }^{2}$ School of Chemical and Biological Engineering, Seoul National University, Seoul, Republic of Korea. \\ ${ }^{3}$ Department of Biomedical Engineering, Korea University of Science and Technology, Daejeon, Republic of Korea. \\ ${ }^{4}$ Department of Chemical Engineering, Soongsil University, Seoul, Republic of Korea. \\ ${ }^{5}$ Division of Mass Spectrometry Research, Korea Basic Science Institute, Ochang, Republic of Korea. \\ ${ }^{6}$ Department of Bioengineering, University of California San Diego, La Jolla, CA, USA. \\ $\S$ Contributed equally to this work.
}

\begin{abstract}
Control of cell-matrix adhesion has become an important issue in the regulation of stem cell function. In this study, a maltose-binding protein (MBP)-linked basic fibroblast growth factor (FGF2)-immobilised polystyrene surface (PS-MBP-FGF2) was applied as an artificial matrix to regulate integrin-mediated signalling. We sought to characterise human mesenchymal-stem cell (hMSC) behaviour in response to two different mechanisms of cell adhesion; (i) FGF2-heparan sulphate proteoglycan (HSPG)-mediated adhesion vs. (ii) fibronectin (FN)integrin-mediated adhesion. Heparin inhibited hMSC adhesion to PS-MBP-FGF2 but not to FN-coated surface. The phosphorylation of focal adhesion kinase, cytoskeletal re-organisation, and cell proliferation were restricted in hMSCs adhering to PS-MBP-FGF2 compared to FN-coated surface. Expression of MSC markers, such as CD105, CD90 and CD166, decreased in hMSCs expanded on PS-MBP-FGF2 compared to expression in cells expanded on FN-coated surface. hMSCs that were expanded on FN-coated surface differentiated into osteogenic and adipogenic cells more readily than those that were expanded on PS-MBP-FGF2. Furthermore, we characterised the N-linked glycan structures of hMSCs depending on the cell adhesion mechanism using mass spectrometry (MS)-based quantitative techniques. MS analysis revealed that 2,3-sialylated glycans, a potential marker of stem cell function, were more abundant on hMSCs expanded on FN-coated surface than on those expanded on PS-MBP-FGF2. Thus, the differentiation potential of hMSCs is controlled by the type of adhesion substrate that might provide an idea for the design of biomaterials to control stem cell fate. Elucidation of the glycan structure on the cell membrane may help characterise hMSC function.
\end{abstract}

Keywords: Artificial matrix, cell differentiation, human mesenchymal stem cells (hMSCs), immobilised basic fibroblast growth factor, glycomics.
*Address for correspondence:

Sang-Heon Kim

Center for Biomaterials

Medical Engineering Institute

Korea Institute of Science and Technology

Seoul 136-79

Republic of Korea

Telephone Number: 82-2-958-5344

FAX Number: 82-2-958-5308

E-mail: skimbrc@kist.re.kr

\section{Introduction}

Mesenchymal stem cells (MSCs) are found in the bone marrow and are separated from isolated bone marrow by centrifugation. Human MSCs (hMSCs) are considered an attractive cell source in regenerative medicine, including cell therapy and tissue engineering (Bianco et al., 2012; Wexler et al., 2013). MSCs are typically characterised as plastic-adherent, spindle-shaped cells that grow in a monolayer. Despite major recent progress regarding the characteristics of MSCs, proper identification of MSCs remains a challenge. In several reports, MSCs are identified by expression of the surface markers CD29, CD90, CD105, and CD166 and lack expression of CD34 and CD45 (Carvalho et al., 2009; De Schauwera et al., 2011; Ross et al., 1998). MSCs have been shown to differentiate into a variety of cells in different lineages, such as osteoblasts, adipocytes, chondrocytes and endothelial cells (Conget et al., 1999; Chamberlain et al., 2007). In vitro and in vivo, cell adhesion to the extracellular matrix (ECM) is critical for determining cellular fates, such as proliferation, migration, and differentiation (Giancotti and Ruoslahti, 1999). Biofunctional materials have been designed as an artificial matrix to stimulate cell adhesion and particular cellular functions, and the resulting field has been termed "matrix engineering" (Kim et al., 2004). Of interest in stem cell and tissue engineering research, studies involving cellular adhesion to an artificial matrix have recently increased (Guilak et al., 2009). The engineering of geometrically and biochemically functionalised surfaces that are designed and processed for stem cell adhesion is a challenging task. Significant progress has been made in the use of functionalised surfaces to control the stem cell phenotype, multipotency, and cell growth by controlling 
cell adhesion (Giancotti et al., 1999; Kim et al., 2004; Guilak et al., 2009); For example, a nanoscale-patterned surface was useful for controlling long-term maintenance of MSC multipotency (McMurray et al., 2011); Hydrophobic nanopillar surfaces significantly enhance the adhesion, growth, and osteogenic differentiation of rat MSCs (Brammer et al., 2011); Chemically modified glass surfaces affect cell behaviour in terms of viable cell adhesion, morphology, and mRNA expression, providing the means to alter the differentiation potential of MSCs (Curran et al., 2005); MSCs differentiate into a specific lineage depending on the stiffness of the surface upon which they are cultured (Engler et al., 2006).

The $\mathrm{COOH}$-terminal heparin-binding domains (HBDs) within fibronectin have been reported to promote cellular adhesion to fibronectin through cell surface heparan sulphate proteoglycans (HSPGs), indicating that heparin, a highly sulphated glycosaminoglycan, is another mediator of cell-fibronectin interaction for neural and bone-derived stem cells (Dalton et al., 1995; Kusano et al., 2000). We previously demonstrated that HSPGs on human adiposederived stromal cell (hASC) membranes are involved in cell adhesion via the heparin-binding region of fibronectin (Kim et al., 2009). HSPGs also bind basic fibroblast growth factor (FGF2) and are required for the interaction between FGF2 and the FGF receptor (FGFR) and the resulting signalling (Lanner et al., 2010). Maltose-binding protein (MBP)-fusion proteins, such as MBP-HBD, MBP-vascular endothelial growth factor (VEGF), and MBP-FGF2, which are genetically engineered recombinant proteins, were synthesised as artificial matrix proteins whose interactions are mediated by HSPGs for hASC adhesion and were characterised based on immobilisation and biochemical and biological activities (Han et al., 2009; Kim et al., 2009; Kang et al., 2012). Our data showed that the MBP fusion proteins adsorbed to the PS surface as a monolayer and were thus exposed extending from the PS surface according to the results of QCM-D (Quartz Crystal Microbalance with Dissipation monitoring) and heparin binding assays (Han et al., 2009; Kang et al., 2012). In particular, hASCs adhered with a higher affinity to an FGF2-immobilised substrate, indicating that cells adhered to the substrate through a specific HSPG-mediated interaction.

Cell morphology regulates biological processes, such as proliferation, differentiation and the commitment of adult stem cells to specific lineages. For example, although hMSCs differentiate into osteoblasts under culture conditions in which their spread out shape is maintained, hMSCs that maintain a rounded morphology differentiate into adipocytes (McBeath et al., 2004). We reported that hASCs differentiate more readily into adipocytes than osteoblasts on surfaces with immobilised FGF2, suggesting that hASC differentiation is strongly correlated with the cell adhesion mechanism and that surfaces displaying immobilised FGF2 can serve as a unique artificial matrix for regulating integrin-mediated signalling and stem cell differentiation through FGF2-HSPG interactions (Kang et al., 2012).

Studies on stem cell glycosylation are limited, but this is an emerging field in stem cell biology and biotechnology as well as glycobiology. Recent studies have suggested that glycans on the plasma membrane of stem cells change during differentiation, and thus contribute to identification, isolation and purification of specific stem cell lineages from a heterogeneous population for therapeutic transplantation (Lanctot et al., 2007). For example, stage-specific embryonic antigenic glycosphingolipid-derived glycans (SSEA-3 and SSEA-4) and tumour-rejection antigenic $O$-glycans (Tra-1-60 and Tra1-81) are commonly used as markers for the identification of specific stem cell type (Schopperle and DeWolf, 2007; Muramatsu and Muramatsu, 2004).

Most of the studies for validation of specific stem cells have been performed using carbohydrate-specific antibodies or lectins (Wearne et al., 2006; Adewumi et al., 2007). However, antibody- and lectin-based methods are indirect and only tentatively characterise the glycan structures because they only determine the non-reducing ends of glycans that are recognised by the lectins or antibodies. Lately, mass spectrometry (MS)-based glycomics have been applied in identification of stem cell surface glycosylation, such as human haematopoietic stem and progenitor cells (Hemmoranta et al., 2007), hMSCs (Heiskanen et al., 2009; Hamouda et al., 2013), and human embryonic stem cells (An et al., 2012; Satomaa et al., 2009).

In this study, we hypothesised that HSPG-mediated cell adhesion did not activate integrin-mediated cell signalling in hMSCs and that cell function is affected by signalling. Furthermore, we sought to find glycosylation (sialylation) differences on the surface of hMSCs that depend on the cell adhesion mechanism and provide information for glycomics studies based on matrix biomaterials in the stem cell research field.

\section{Materials and Methods}

\section{Materials}

MBP-fused proteins (MBP-FGF2, MBP-VEGF and MBPHBD) were produced according to the method described previously (Han et al., 2009; Kim et al., 2009; Kang et al., 2012). Peroxidase-conjugated anti-rabbit IgG, antimouse IgG and mouse IgG1 were purchased from Pierce (Rockford, IL, USA). Recombinant human FGF2 and bovine serum albumin (BSA; A9418) were supplied by Sigma (St Louis, MO, USA). Dulbecco's modified Eagle's medium (DMEM) was supplied by Gibco (Grand Island, NY, USA). Culture plastic wares were purchased from Becton Dickinson (Franklin Lakes, NJ, USA). Fibronectin was supplied by Invitrogen (Carlsbad, CA, USA). All other chemical reagents were purchased from Sigma unless otherwise described.

\section{hMSC culture}

hMSCs (Center for Regenerative Medicine, Texas A \& M University, College Station, TX, USA) were expanded at $37^{\circ} \mathbf{C}, 5 \% \mathrm{CO}_{2}$ in growth medium consisting of high glucose DMEM, $8.97 \%$ foetal bovine serum (FBS; Hyclone/ThermoScientific, Rockford, MD, USA) $1.8 \mathrm{mM}$ L-glutamine (Invitrogen), $100 \mathrm{U} / \mathrm{mL}$ penicillin and streptomycin (Invitrogen). For each passage the cells were 
A
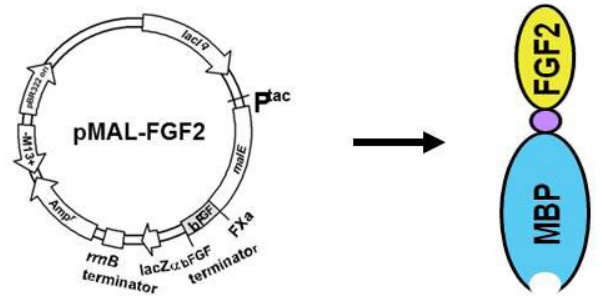

Fig. 1. (A) Scheme of PS-MBP-FGF2 preparation. AFM image of PS (B) and PS-MBP-FGF2 (C); PS coated with $10 \mu \mathrm{g} /$ $\mathrm{mL}$ MBP-FGF2. Samples were analysed by commercial atomic force microscope (AFM, Park System, Sunnyvale, CA, USA) using non-contact high resonance frequency reflex coating (NCHR) cantilever at room temperature. Average values of cantilever length, width and thickness are $125 \mu \mathrm{m}$, $30 \mu \mathrm{m}$ and $4 \mu \mathrm{m}$ respectively. The tip frequency is $330 \mathrm{kHz}$ and force constant of the tip is $42 \mathrm{~N} / \mathrm{m} .1 \times 1 \mu \mathrm{m}$ size of image were obtained by non-contact mode AFM.
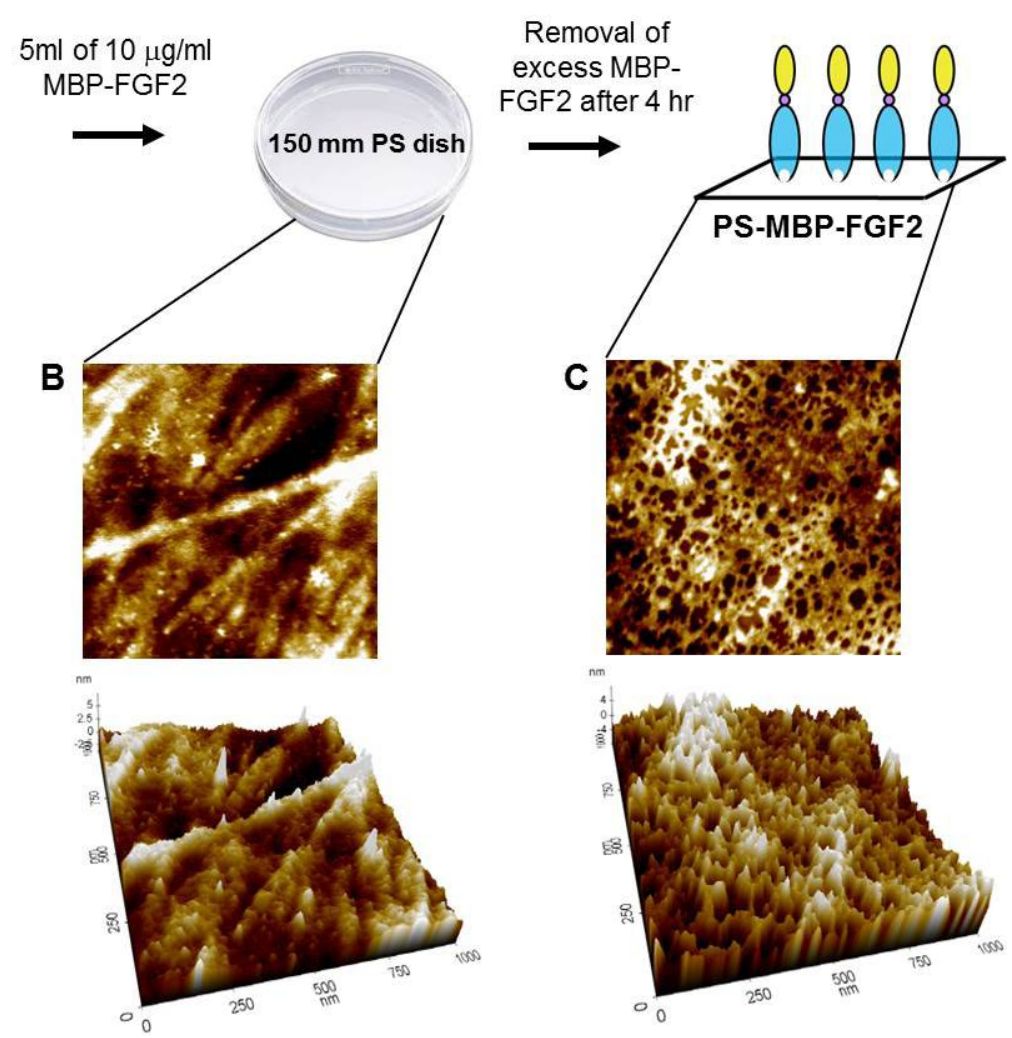

plated at a density of $5 \times 10^{3}$ cells $/ \mathrm{cm}^{2}$ and passaged at $70 \%$ confluence using $0.25 \%$ trypsin-EDTA (Invitrogen). Fifth passage (P5) hMSCs were used for all the experiments. The morphology of adherent hASC was observed using a phase contrast microscope (Nikon TE 2000-U, Tokyo, Japan).

\section{Preparation of FGF2-immobilised surface}

A scheme for the preparation of FGF2-immobilised surface is presented in Fig. 1A. A substrate with immobilised FGF2 was created using a maltose-binding protein (MBP) as a physical linker for the immobilisation of FGF2 to hydrophobic polystyrene surface (PS) (PS-MBP-FGF2). MBP-FGF2 $(10 \mu \mathrm{g} / \mathrm{mL})$ or fibronectin (FN; $20 \mu \mathrm{g} /$ $\mathrm{mL}$ ) dissolved in phosphate buffered saline (PBS) was spontaneously adsorbed to PS micro-well plates or $150 \mathrm{~mm}$ Petri dishes (Non-tissue culture treated) for $4 \mathrm{~h}$ at $37^{\circ} \mathrm{C}$. Excess protein solution was removed from the PS surface. The plates were then washed three times with PBS. Atomic force microscopy (AFM) was used to characterise the topography of PS surfaces coated with MBP-FGF2, which showed the PS surface to be densely covered by $10 \mu \mathrm{g} / \mathrm{mL}$ of MBP-FGF2 (Ktari et al., 2010) (Fig. 1C).

\section{Cell adhesion and proliferation assay}

For a cell adhesion assay, hMSCs were suspended at $7 \times 10^{4}$ cells $/ \mathrm{mL}$ in FBS-free DMEM, plated at $4.9 \times 10^{4}$ cells per well in triplicate into 24-well PS plates coated with proteins, and allowed to adhere for $1 \mathrm{~h}$ at $37^{\circ} \mathrm{C}$. Nonadherent cells were removed from each well by washing with PBS and protein was extracted from the adhered cells with lysis solution $(0.25 \% \mathrm{NaOH}$ and $0.5 \% \mathrm{SDS})$, as described previously (Kim et al., 2001). For inhibitory effect of heparin on hMSC adhesion to PS-MBP-FGF2, the 96-well plates that had been coated with proteins were pre-incubated with a given concentration of heparin dissolved in DMEM for $1 \mathrm{~h}$ at $37^{\circ} \mathrm{C}$. hMSC suspension $\left(0.2 \mathrm{~mL}\right.$ of $1 \times 10^{5}$ cells $\left./ \mathrm{mL}\right)$ was seeded in the plates after removing heparin solution. The percent of cells adhered was determined from the amount of protein measured by the BCA assay (Pierce). The absorbance of each well was measured using a UV-microplate reader (EMAX Precision Microplate Reader, Molecular Devices, Sunnyvale, CA, USA) at $562 \mathrm{~nm}$.

For a cell proliferation assay, hMSCs were suspended at $1.4 \times 10^{4}$ cells $/ \mathrm{mL}$ in growth medium, plated at $1 \times 10^{4}$ cells per well in triplicate into 24-well PS plates coated with FN and MBP-FGF2, and cultured in a humidified atmosphere at $37{ }^{\circ} \mathrm{C}$ with $5 \% \mathrm{CO}_{2}$ and $95 \%$ air for a given time. The cultured cells were collected using $0.25 \%$ trypsin-EDTA and counted by an automated cell counter (ADAM-MC; NanoEnTek, Seoul, Korea).

\section{Western blot analysis}

hMSCs were solubilised in lysis buffer $(20 \mathrm{mM}$ Tris- $\mathrm{HCl}$, pH 7.4, $150 \mathrm{mM} \mathrm{NaCl}, 1 \mathrm{mM}$ EDTA, $1 \%$ Triton X-100, $0.1 \%$ SDS, $1 \mathrm{mM}$ phenylmethylsulphonyl fluoride, $1 \mu \mathrm{g} / \mathrm{mL}$ leupeptin, $2 \mu \mathrm{g} / \mathrm{mL}$ aprotinin) for $1 \mathrm{~h}$ at $4{ }^{\circ} \mathrm{C}$. Lysates then were clarified by centrifugation at $15,000 \mathrm{x} g$ for $30 \mathrm{~min}$ at $4{ }^{\circ} \mathrm{C}$, diluted in Laemmli sample buffer containing $2 \%$ sodium dodecyl sulphate and $5 \%(\mathrm{v} / \mathrm{v})$ 2-mercaptoethanol, and heated for $5 \mathrm{~min}$ at $90^{\circ} \mathrm{C}$. Proteins were separated by SDS-polyacrylamide gel electrophoresis (PAGE) using $8 \%$ resolving gels followed by transfer to nitrocellulose membranes (Bio-Rad, Hercules, CA, USA). 
The membranes were incubated with primary antibody for $1 \mathrm{~h}$ at room temperature. For detection, peroxidaseconjugated anti-mouse $\operatorname{IgG}$ or anti-rabbit $\operatorname{IgG}$ and the enhanced chemiluminescent (ECL) method (Pierce) were used, as described by the manufacturer. Membranes were scanned to create chemiluminescent images and to quantify with an image analyser (LAS3000; Fusifilm, Tokyo, Japan).

\section{Immunofluorescence staining}

hMSCs $\left(7 \times 10^{5}\right.$ cells $)$ were plated in $150 \mathrm{~mm}$ PS Petri dishes (Becton Dickinson) coated with FN and MBPFGF2 and expanded in a humidified atmosphere at $37^{\circ} \mathrm{C}$ with $5 \% \mathrm{CO}_{2}$ and $95 \%$ air for $5 \mathrm{~d}$. The expanded cells $\left(2 \times 10^{4}\right)$ were plated on Lab-Tek II 8-well glass chamber slides (Thermo Scientific, Rochester, NY, USA) for $1 \mathrm{~d}$ at $37{ }^{\circ} \mathrm{C}$ with $5 \% \mathrm{CO}_{2}$ and $95 \%$ air. The morphology of adherent hMSCs was observed using a phase contrast microscope (Nikon TE 2000-U, Tokyo, Japan). Indirect immunofluorescence staining was performed using a standard procedure. In brief, cells were blocked with $5 \%$ BSA/PBS $\left(1 \mathrm{~h}, 25^{\circ} \mathrm{C}\right)$, then washed twice with PBS. The cells were stained in $1 \% \mathrm{BSA} / \mathrm{PBS}$ with either isotype controls or antigen specific antibodies for $60 \mathrm{~min}$. The used antibodies were human CD29 (Millipore, County Cork, Ireland), CD90 (BD Biosciences, San Jose, CA, USA), CD105 (Caltac Laboratories, Burlingham, CA, USA), and CD34 (Millipore, Billerica, MA, USA). The cells were washed three times with $0.5 \% \mathrm{BSA} / \mathrm{PBS}$.

For actin staining of cultured hMSCs, hMSCs were fixed with $4 \%$ paraformaldehyde at room temperature for 5 min. hMSCs were washed twice with PBS and treated with $0.1 \%$ Triton X-100/PBS for $1 \mathrm{~min}$, then washed extensively in PBS. The cells were incubated with $10 \mu \mathrm{g} /$ $\mathrm{mL}$ fluorescent phalloidin conjugate solution (PhalloidinTRITC, Sigma) for $40 \mathrm{~min}$. Stained cells were observed using a fluorescence microscope (DXM 1200F, Nikon, Tokyo, Japan).

\section{Flow cytometry}

hMSCs expanded on $150 \mathrm{~mm}$ PS Petri dishes coated with MBP-FGF and FN for $5 \mathrm{~d}$ were resuspended and washed with PBS containing $0.5 \% \mathrm{BSA} / \mathrm{PBS}$. hMSCs were stained in $\mathrm{PBS}$ containing $1 \% \mathrm{BSA} / \mathrm{PBS}$ with either isotype controls or antigen specific antibodies for $60 \mathrm{~min}$. The used antibodies were human CD29 (Beckman Coulter, Danvers, MA, USA), CD90 (BD Biosciences), CD105 (Caltac Laboratories) and CD166 (BD Biosciences). The cells were washed three times with PBS containing $0.5 \% \mathrm{BSA} / \mathrm{PBS}$. After washes, cells were resuspended in PBS and analysed by flow cytometer (Cytomics FC 500; Beckman Coulter). Isotype control IgG was used as a negative control. The mean fluorescence intensity (MFI) value for each antibody was calculated by dividing the MFI value of the positively stained cells by that of cells stained with an isotype control antibody.

\section{Adipogenesis and osteogenesis of hMSCs}

hMSCs expanded for $5 \mathrm{~d}$ on $150 \mathrm{~mm}$ PS Petri dishes coated with MBP-FGF2 and FN were plated at $1 \times 10^{4}$ cells $/ \mathrm{cm}^{2}$ into 24 -well tissue culture plates and cultured for $2 \mathrm{~d}$ before being changed to adipogenic medium (maintenance medium with $10 \mu \mathrm{g} / \mathrm{mL}$ insulin, $115 \mu \mathrm{g}$ / $\mathrm{mL}$ methyl-isobutylxanthine, $1 \mu \mathrm{M}$ dexamethasone, and $20 \mu \mathrm{M}$ indomethacin) or osteogenic medium (maintenance medium with $10 \mathrm{nM}$ dexamethasone, $25 \mu \mathrm{g} / \mathrm{mL}$ ascorbic acid, and $10 \mathrm{mM} \beta$-glycerophosphate), as previously reported (Ayala et al., 2011). The cells were cultured for up to $21 \mathrm{~d}$ for adipogenesis or osteogenesis, respectively, with a medium change every other day. The cells were stained with Oil Red O (Sigma) for lipid droplet detection or Alizarin Red S for calcium detection. For a quantitative $\mathrm{Ca}^{2+}$ assay, the Colorimetric Calcium Assay Kit (BioVersion, Milpitas, CA, USA) was used, as described by the manufacturer.

\section{Fractionation and deglycosylation of hMSC membrane proteins}

All the steps were performed on ice using pre-chilled solution (at $4{ }^{\circ} \mathrm{C}$ ). Centrifugation and incubation were carried out at $4{ }^{\circ} \mathrm{C}$. All fractions were stored at $-20{ }^{\circ} \mathrm{C}$ until further use. Each of the hMSCs $\left(10^{6} \sim 10^{7}\right.$ cells $)$ was washed twice with PBS. The cells were lysed by brief sonication, centrifuged at $100,000 \times \mathrm{g}$ for $1 \mathrm{~h}$, and then the pellet was washed three times with PBS to remove the cytosolic fraction. The washed pellet was resuspended in $50 \mathrm{mM}$ sodium phosphate buffer $(\mathrm{pH}$ 7.5) for further enzyme reaction. The membrane proteins were denatured at $95{ }^{\circ} \mathrm{C}$ for $3 \mathrm{~min}$. After cooling to room temperature, the proteins were treated with peptide $N$-glycosidase F (PNGase F, Roche, Mannheim, Germany) followed by incubation at $37{ }^{\circ} \mathrm{C}$ for $16 \mathrm{~h}$. The $N$-deglycosylated proteins were precipitated by adding ethanol and then kept at $-20{ }^{\circ} \mathrm{C}$ for $2 \mathrm{~h}$, followed by centrifugation at $13,500 \mathrm{rpm}$ for $15 \mathrm{~min}$. The released $\mathrm{N}$-glycans in the supernatant were dried for further purification.

\section{Purification and exoglycosidase digestion of $N$-linked glycans}

The released $N$-linked glycans were purified using a HyperSep Hypercarb SPE cartridge (Thermo Scientific, Bellefonte, PA, USA) to remove the salts and other contaminants. The purification protocol was as follows: First, the cartridge was washed with $30 \%(\mathrm{v} / \mathrm{v})$ acetic $\mathrm{acid} /$ water followed $0.1 \%$ trifluoroacetic acid (TFA) in $50 \%(\mathrm{v} / \mathrm{v})$ acetonitrile $(\mathrm{ACN}) /$ water. Next, the cartridge was equilibrated with $0.1 \%$ TFA in $5 \%(\mathrm{v} / \mathrm{v}) \mathrm{ACN} /$ water, and then the $N$-glycan solution was applied to the cartridge. Subsequently, the cartridge was washed with water and $0.1 \%$ TFA in $5 \%(\mathrm{v} / \mathrm{v}) \mathrm{ACN} /$ water continuously. The glycans were eluted with $0.1 \%$ TFA in $50 \%(\mathrm{v} / \mathrm{v})$ ACN/water. The collected glycans were dried for further steps. The purified $N$-linked glycans were treated with Glyko Sialidase S from Streptococcus pneumoniae (Prozyme, Hayward, CA, USA) followed by incubation in $50 \mathrm{mM}$ sodium phosphate buffer $\left(\mathrm{pH} \mathrm{6.0)}\right.$ ) at $37^{\circ} \mathrm{C}$ for $16 \mathrm{~h}$. The desialylated glycans were purified from exoglycosidase enzyme using Amicon ${ }^{\circledR}$ Ultra Centrifugal Filters (Millipore). 

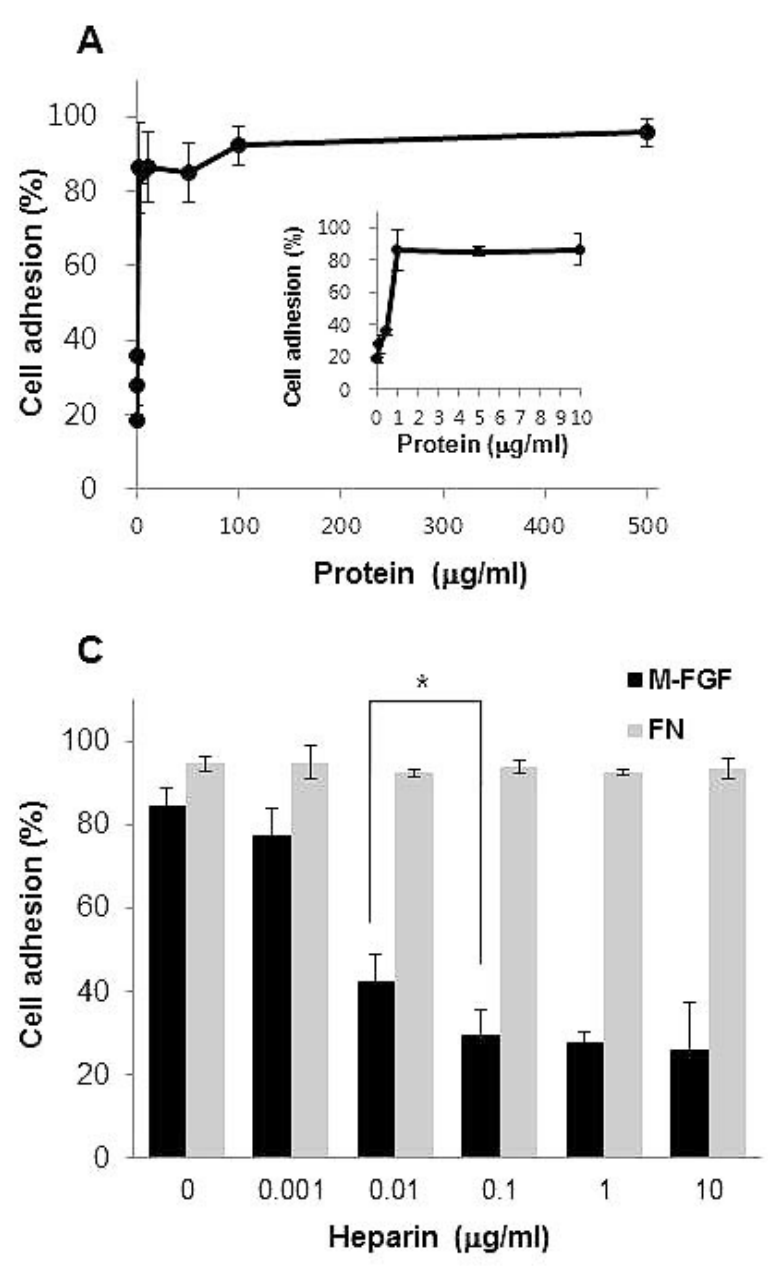

Permethylation of N-linked glycans

The purified $N$-linked glycans were permethylated using the solid-phase permethylation method (Kang et al., 2008). Briefly, micro spin columns (Harvard Apparatus, Holliston, MA, USA) were packed with $\mathrm{NaOH}$ beads. Next, the spin column was washed with dimethyl sulphoxide (DMSO) by centrifugation and then the $N$-glycan sample, which is suspended in $141.6 \mu \mathrm{L}$ of DMSO, $52.8 \mu \mathrm{L}$ of iodomethane $\left(\mathrm{CH}_{3} \mathrm{I}\right)$, and $5.6 \mu \mathrm{L}$ of water, was applied to the $\mathrm{NaOH}-$ packed spin column by centrifugation. The sample was then reloaded at least eight times. The spin column was washed with $100 \mu \mathrm{L}$ of ACN followed by centrifugation for complete collection. Permethylated samples were extracted with chloroform and water. Finally, the permethylated $N$-glycans in the chloroform layer were dried for further MS analyses.

\section{MALD-TOF MS and MALDI-QIT-TOF MS/MS analysis}

Sample solution $(0.5 \mu \mathrm{L})$ was mixed with $0.5 \mu \mathrm{L}$ of 2,5-dihydroxybenzoic acid (DHB) solution $(30 \mathrm{mg} / \mathrm{mL}$ in $30 / 70(\mathrm{v} / \mathrm{v})$ water/ACN). One $\mu \mathrm{L}$ of the mixture was spotted onto a stainless steel MALDI plate and dried at room temperature. MS analysis was performed using a MALDI-TOF (matrix-assisted laser desorption/ionisation time-of-flight) MS instrument with an Autoflex system from Bruker Daltonics (Bruker, Bremen, Germany). The analysis parameters were as follows: positive-ion and reflectron mode, detector gain $=3.9$ and laser power

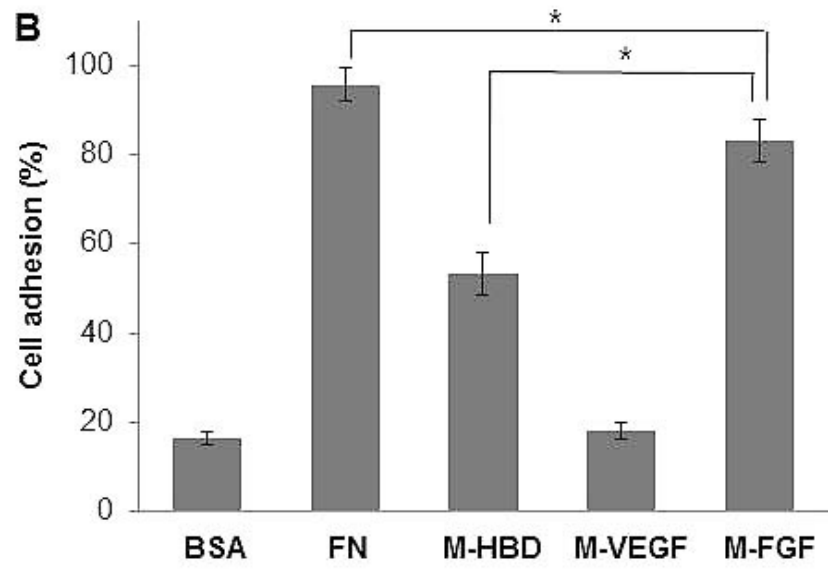

Fig. 2. Adhesion of hMSC to PS-MBP-FGF2. (A) hMSC adhesion to PS-MBP-FGF2 in a dose-dependent manner $(0.1 \sim 500 \mu \mathrm{g} / \mathrm{mL})$. (B) Adhesion of hMSC to various matrices; PS plates coated with $100 \mu \mathrm{g} / \mathrm{mL}$ MBP-HBD (M-HBD) and MBP-VEGF (M-VEGF) and $10 \mu \mathrm{g} / \mathrm{mL}$ MBP-FGF2 (M-FGF), with PS plates coated with $1 \%$ $\mathrm{w} / \mathrm{v}$ BSA or $20 \mu \mathrm{g} / \mathrm{mL}$ fibronectin (FN) serving as a negative or positive control, respectively. (C) Inhibitory effect of heparin on hMSC adhesion to PS-MBP-FGF2. All values were normalised to the percentage of adhesion of the maximum, which was taken as $100 \%$; $* p<0.05$ student's $t$ test.
$=70 \%$, peptide calibration standard II (Bruker) of Angiotensin II ( $m / z$ 1046.54), Angiotensin I ( $m / z$ 1296.68), Substance P ( $\mathrm{m} / z$ 1347.74), Bombesin $(\mathrm{m} / z$ 1619.82), ACTH1-17 ( $m / z$ 2093.09), ACTH18-39 ( $m / z$ 2465.20), Somatostatin $(m / z$ 3147.47). Ten thousand different spots were scanned to acquire mass spectra data. Data acquisition and processing were performed with flex Analysis 3.3 software (Bruker). MS/MS analysis was performed using an Axima Resonance MALDI-quadrupole ion trap (QIT)TOF instrument (Shimadzu, Manchester, UK). The analysis parameters were as follows: positive-ion and reflectron mode. The TOF detector was calibrated as described above. Data acquisition and processing were performed with Launchpad 2.9.3.20110624 software (Kratos Analytical Ltd, Manchester, UK).

\section{Results}

\section{Characterisation of hMSC adhesion to an FGF2- immobilised substrate}

To evaluate the affinity of hMSCs to adhere to PS-MBPFGF2, we carried out cell adhesion assays according to the coating density of the immobilised proteins using a bovine serum albumin-coated PS surface as a negative control. The adhesion of hMSCs to PS-MBP-FGF2 was dose dependent (Fig. 2A) and comparable to adhesion on an FN-coated PS surface (Fig. 2B). hMSCs rarely adhered to 
A

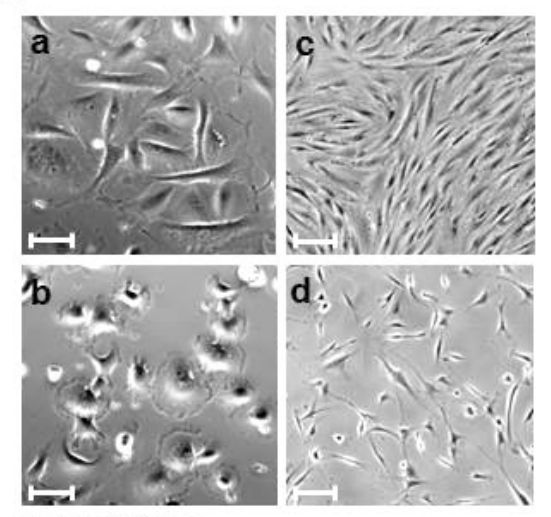

Scale bar $=100 \mu \mathrm{m}$

B
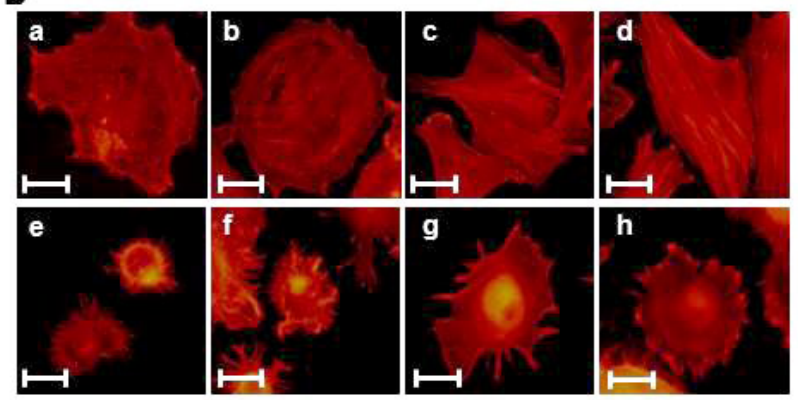

Scale bar $=25 \mu \mathrm{m}$
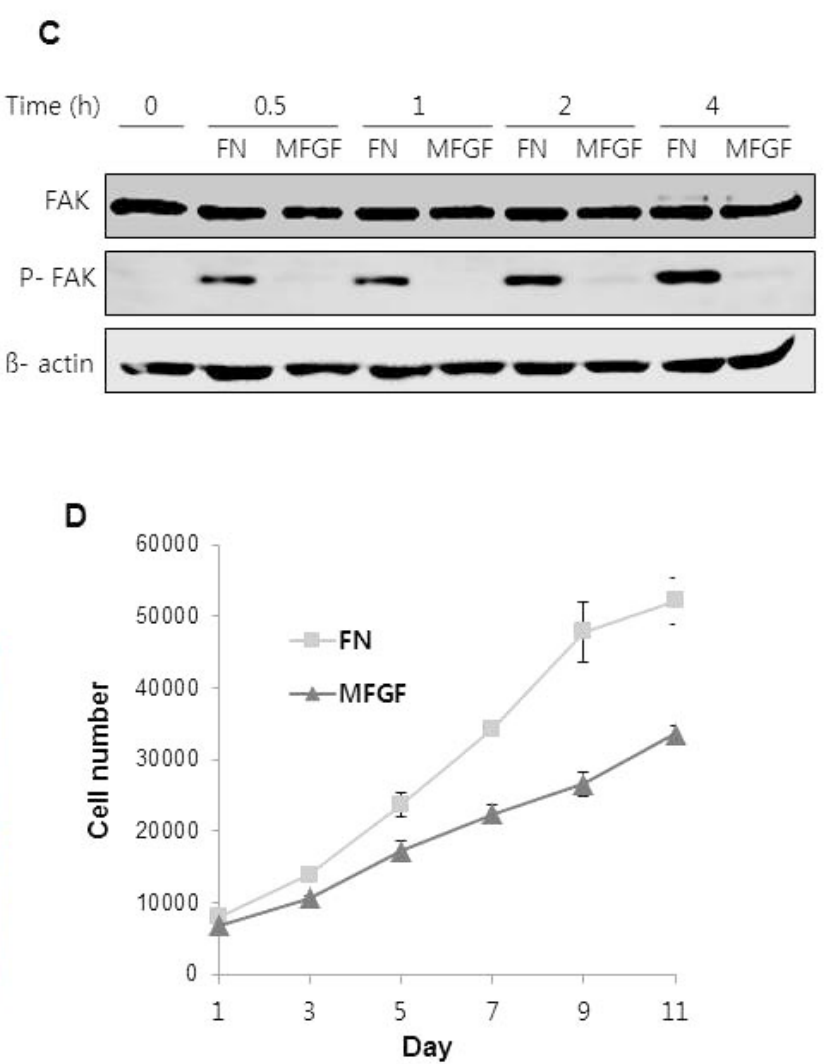

Fig. 3. hMSC behavior depending on cell adhesion. (A) Morphology of hMSCs depending on cell adhesion; hMSCs were cultured for $2 \mathrm{~h}$ ( $\mathrm{a}$ and $\mathrm{b}$ ) and $5 \mathrm{~d}$ (c and d) on PS-MBP-FGF2 (b and d) and FN substrate (a and c). (B) Actin staining of hMSCs cultured for 2 (a and e), 4 (b and f), 12 (c and g), and $24 \mathrm{~h}$ ( $\mathrm{d}$ and h) on FN substrate (a-d) and PS-MBP-FGF2 (e-h). (C) FAK phosphorylation of hMSCs depending on the type of adhesion substrate; hMSCs were allowed to adhere on FN substrate (FN) and PS-MBP-FGF2 (MFGF) in serum-free media for an indicated time. (D) Proliferation of hMSCs depending on the type of adhesion substrate (FN vs. PS-MBP-FGF2).

PS-MBP-VEGF and only adhered to PS-MBP-HBD coated with more than $50 \mu \mathrm{g} / \mathrm{mL}$ MBP-HBD. Nearly all cells adhered to PS-MBP-FGF2 coated with more than $1 \mu \mathrm{g} / \mathrm{mL}$ MBP-FGF2 (Fig. 2B). A heparin inhibition assay showed reduction of hMSC adhesion to PS-MBP-FGF2 but not to the FN-coated surface (Fig. 2C). These results indicate that hMSCs adhere to PS-MBP-FGF2 with a greater affinity than to the other heparin-binding protein-coated surfaces and that the adhesion between hMSCs and PS-MBP-FGF2 was mediated by HSPG on the cell membrane.

\section{Control of integrin-mediated behaviour in hMSCs on PS-MBP-FGF2}

Morphology can be used as an indicator of a cell's response to cell-matrix adhesions. The morphology of hMSCs adhering to PS-MBP-FGF2 was compared with the morphology of cells adhering to a FN-coated surface (Fig. 3A). Adherent hMSCs were much more spread out on the FN-coated surface (Fig. 3A-a) than on PS-MBPFGF2 $2 \mathrm{~h}$ after seeding (Fig. 3A-b). hMSCs that adhered to the FN-coated surface maintained a spindle-like structure during culture (Fig. 3A-c), whereas cells that adhered to PS-MBP-FGF2 became slenderer and longer (Fig. 3A-d).

Cell adhesion to the ECM induces reorganisation of cytoplasmic cytoskeletal networks. To further assess the cytoskeletal structure of hMSCs that adhered to PS-MBPFGF2 and the FN-coated surface, we stained actin filaments with palloidin-TRITC (Fig. 3B). hMSC cell bodies were fully spread out on the FN-coated surface compared to PS-MBP-FGF2, and the actin filaments were reorganised in hMSCs that adhered to the FN-coated surface. On the other hand, the actin filaments remained aggregated in the central area of the cell body in hMSCs that adhered to PS-MBP-FGF2.

Integrin-mediated adhesion of cells to the ECM triggers autophosphorylation at the Tyr-397 residue of focal adhesion kinase (FAK) (Schaller et al., 1994). To elucidate whether integrin-mediated signalling occurs in hMSCs cultured on PS-MBP-FGF2, we evaluated the phosphorylation of FAK in hMSCs cultured on PS-MBPFGF2 compared with cells cultured on the FN-coated surface using western blot analysis with an anti-pFAK (Tyr-397) antibody (Fig. 3C). The phosphorylation level of FAK was sustained in the cells that adhered to the FNcoated surface during culture. In contrast, phosphorylated FAK was only faintly detected in hMSCs cultured on PS-MBP-FGF2, even $4 \mathrm{~h}$ after seeding. These results indicate greatly impaired integrin-mediated adhesion of MSCs cultured on FGF2 substrates, confirming adhesion via alternative mechanisms i.e. heparin-mediated binding. 


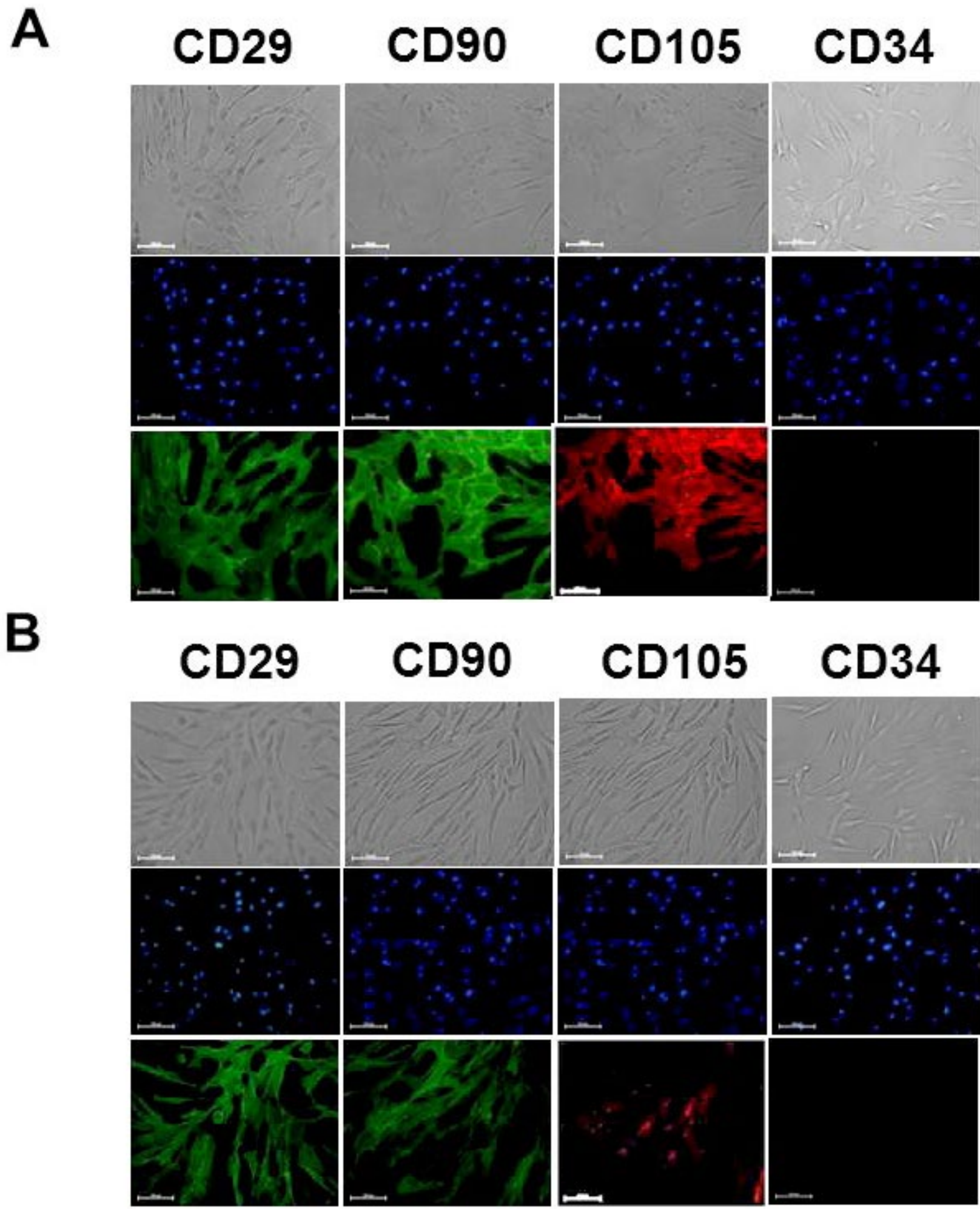

Fig. 4. Immunofluorescence analysis of MSC surface markers. hMSCs expanded on $150 \mathrm{~mm}$ PS Petri dishes coated with FN (A) and MBP-FGF2 (B) were plated on Lab-Tek II 8-well glass chamber slides.

Cell growth is a major phenomenon regulated by integrin-mediated signalling. We examined the effect of the MBP-FGF2 substrate on cell proliferation. The proliferation rate decreased in hMSCs on PS-MBP-FGF2 compared to cells on the FN-coated surface (Fig. 3D). The doubling times were 3 and $5 \mathrm{~d}$ in hMSCs on FN-coated and FGF2 substrates, respectively. We suggest that proliferation of hMSCs is suppressed due to the restricted activation of integrin signalling on a PS surface with immobilised FGF2.

\section{Functional analysis of hMSCs on PS-MBP-FGF2}

Integrins play a key role in cell-ECM adhesion and mediate a wide variety of biological processes such as proliferation and differentiation. To determine if hMSC 

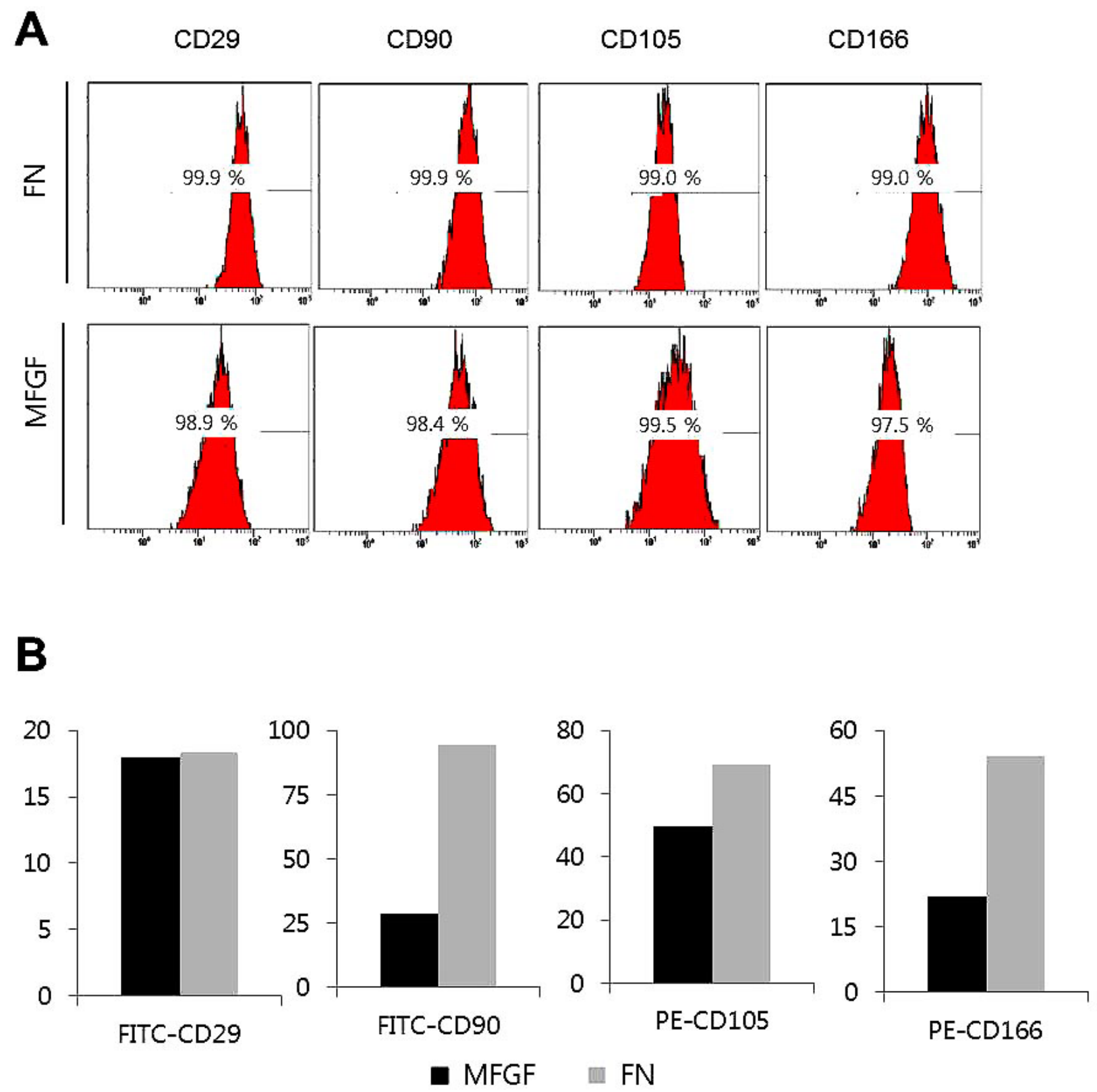

Fig. 5. Flow cytometry analysis of MSC surface markers. (A) The histograms present results of hMSCs expanded on FN substrate (FN) and PS-MBP-FGF2 (MFGF). The x-axis represents the intensity of the fluorescence, the y-axis the entire number of cells. The bar stands for the amount of positive cells. (B) Mean fluorescence intensity (MFI) of CD29-, CD90-, CD105- and CD166-positive hMSCs; The relative strength of intensity was normalised to the value of the highest expression level, which taken as 100 based on the unstained cells. The data shown are to demonstrate an increase or decrease in expression of individual markers. The experiments were performed in biological duplicate for reproducibility.

adhesion to FGF2-immobilised substrate influenced the MSC phenotype, we examined a panel of MSC markers in cells expanded on PS-MBP-FGF2 compared to those expanded on the FN-coated surface. Immunostaining showed that although most hMSCs positively stained for the markers when cultured on PS-MBP-FGF2 (Fig. 4B), the fluorescence intensity appeared weaker compared to cells cultured on the FN-coated surface (Fig. 4A). In Fig. $5 \mathrm{~A}$, fluorescence-activated cell sorting analysis showed that the numbers of cells positive for CD29, CD90, CD105 and CD166 were almost the same in cells cultured on the FN-coated surface (CD29: $99.9 \%$, CD90: $99.9 \%$, CD105:
99.0 \%, and CD166: $99.0 \%$ ) and PS-MBP-FGF2 (CD29: $98.9 \%$, CD90: $98.4 \%$, CD105: $99.5 \%$, and CD166: $97.5 \%$ ). The mean fluorescence index of CD90, CD105 and CD166 decreased in cells cultured on PS-MBP-FGF2 compared to the FN-coated surface (Fig. 5B). These results indicate that expression of MSC markers was reduced in hMSCs cultured on PS-MBP-FGF2. Next, we addressed the differentiation properties of hMSCs expanded on PSMBP-FGF2 compared to those expanded on the FN-coated surface. hMSCs were expanded for $5 \mathrm{~d}$ on PS-MBP-FGF2 or the FN-coated substrate and then cultured on tissue culture plates in osteogenic or adipogenic medium. As 
A

osteogenesis

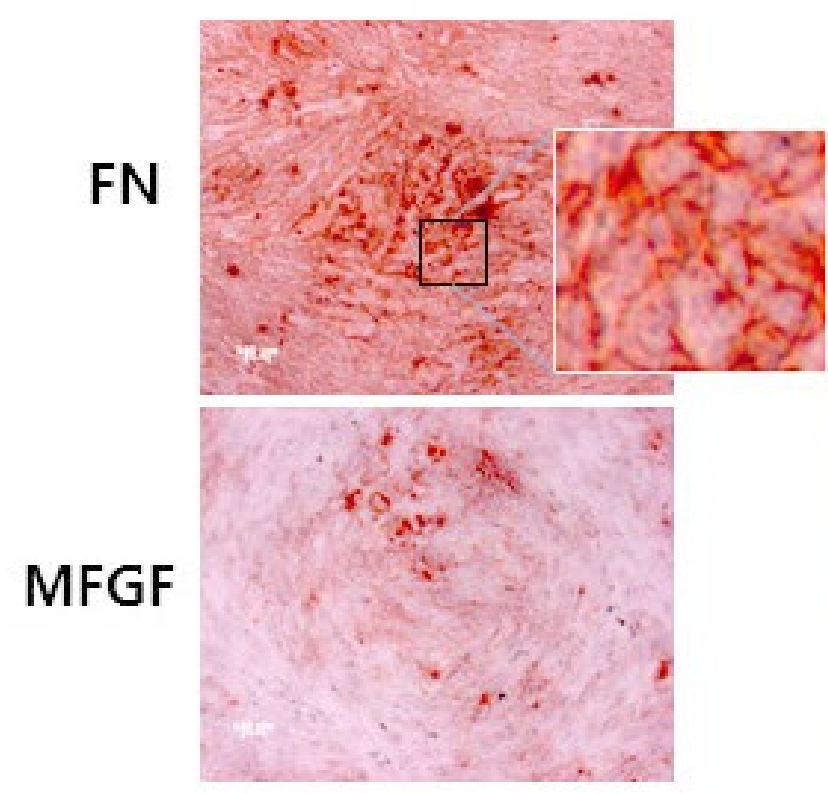

\section{adipogenesis}

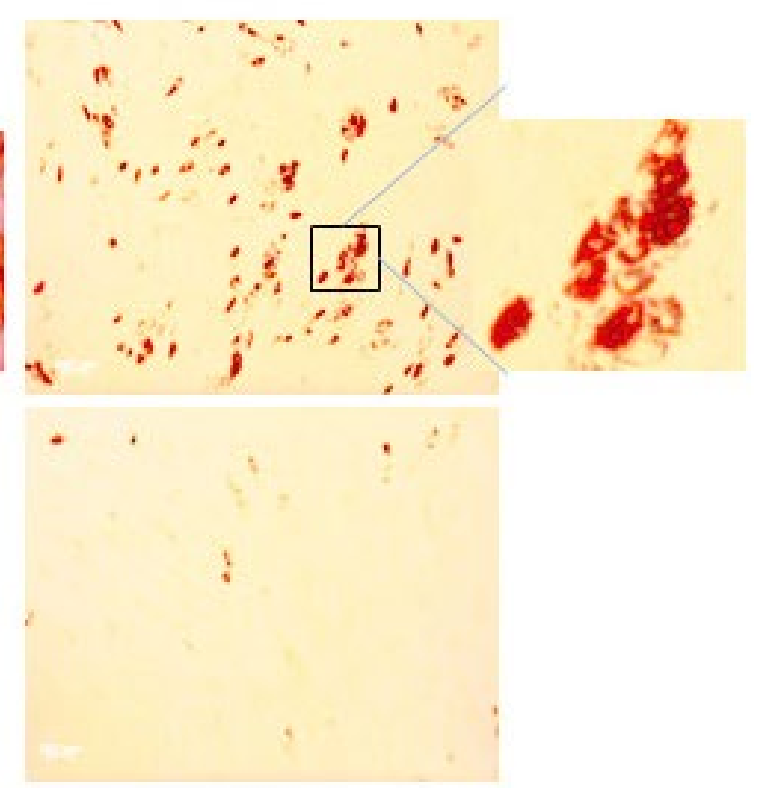

B

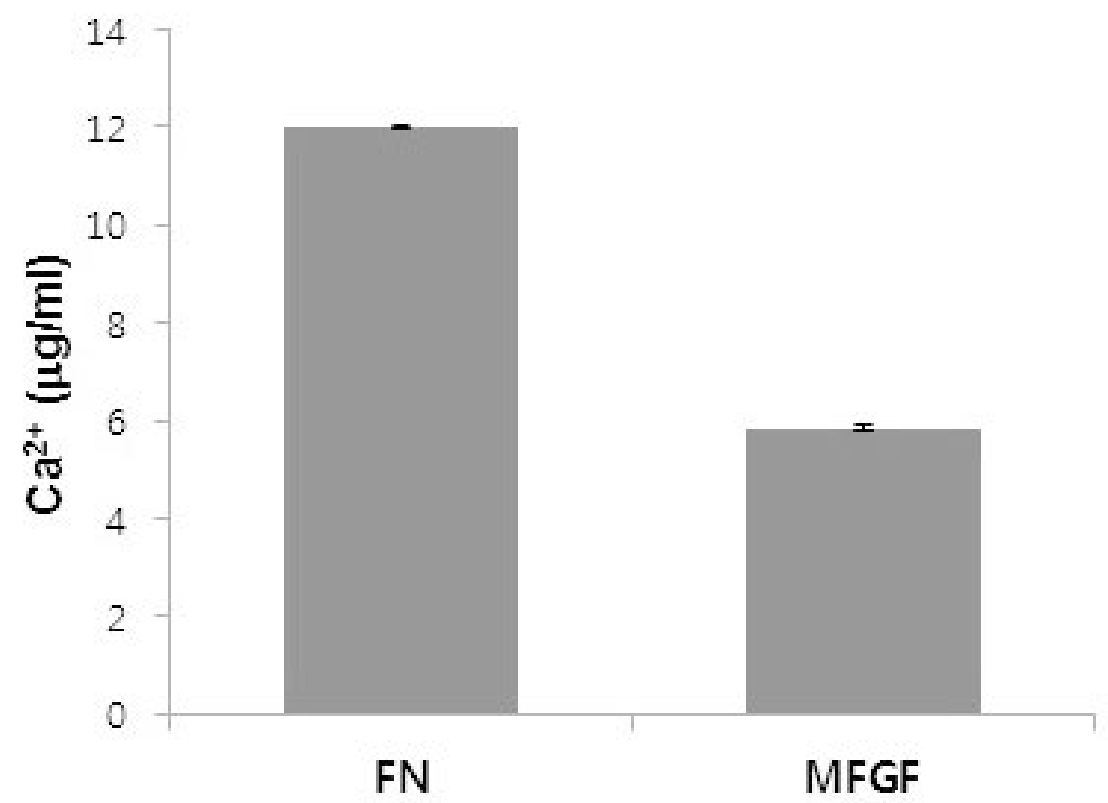

Fig. 6. Osteogenic and adipogenic differentiation of hMSCs depending on the type of adhesion substrate (FN vs. PS-MBP-FGF2). (A) Staining of hMSCs with Alizarin Red S and Oil Red O for the detection of osteogenesis and adipogenesis, respectively. (B) $\mathrm{Ca}^{2+}$ quantitative assay for the detection of osteogenesis.

shown in Fig. 6, many hMSCs that were expanded on the FN-coated substrate were positively stained with Alizarin Red S or Oil Red O, showing calcium deposition or lipid droplets (Fig. 6A, inset) that indicate osteogenic or adipogenic cells, respectively. However, few hMSCs that were expanded on PS-MBP-FGF2 were positive for the osteogenic or adipogenic stains. Thus, the differentiation potential of hMSCs was suppressed when expanded on PS-MBP-FGF2. To quantitatively verify the differentiation property, we measured $\mathrm{Ca}^{2+}$ in cells that were cultured in osteogenic conditions. $\mathrm{Ca}^{2+}$ production showed a decrease of $50 \%$ in hMSCs that were expanded on PS-MBP-FGF2 compared to cells that were expanded on the FN-coated surface (Fig. 6B). Taken together, HSPG-mediated cell adhesion negatively modulates the differentiation potential of hMSCs.

Relative quantitation of N-linked glycans on hMSCs To identify $N$-linked glycans in hMSCs expanded on FNcoated substrate and PS-MBP-FGF2, a glycomics approach 


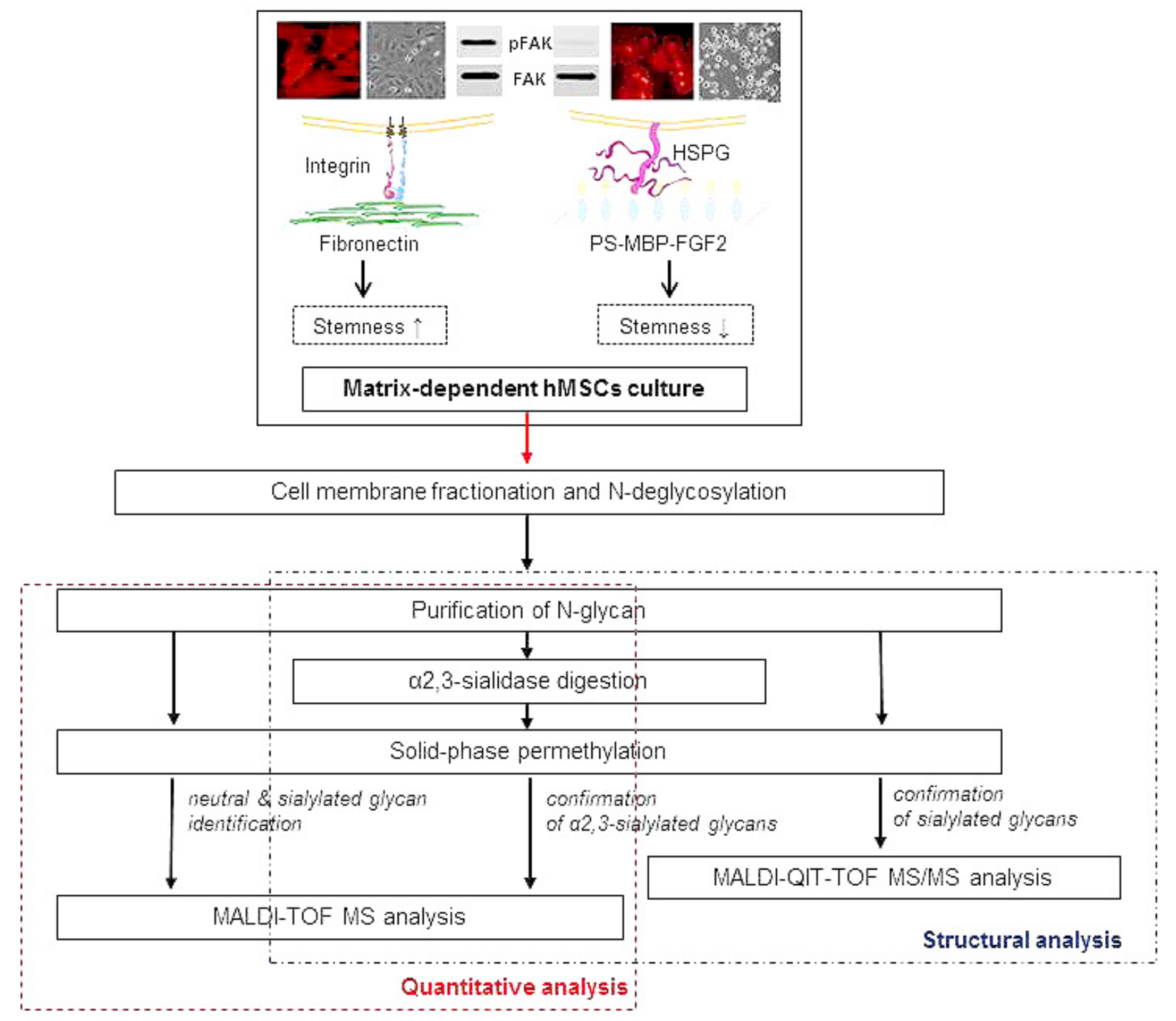

Fig. 7. Scheme of glycomics approach for matrix-dependent hMSC culture. Cell behaviour and differentiation potential of hMSCs on integrin-mediated cell adhesion and HSPG-mediated cell adhesion.

was used according to the scheme described in Fig. 7. Cell membrane proteins were isolated from hMSCs, and then $N$-linked glycans were released from the cell membrane proteins by enzymatic deglycosylation. MALDI-TOF MS analysis coupled with permethylation was performed for quantitative analysis of hMSC $N$-linked glycans. For accurate quantitation, the relative quantity of $N$-linked glycans was calculated from peak intensities of each glycan among the intensities of total $N$-linked glycans. The intensity of each peak was obtained by integrating from the first to the third isotopic peak intensities. Thus, we observed that sialylated $N$-linked glycans were similarly abundant in both hMSCs expanded on the FGF2-immobilised substrate and those expanded on the FN-coated substrate. As shown in Fig. 8, the relative quantity of sialylated glycans in hMSCs cultured on the FN-coated substrate $(76.0 \%)$ was $11.9 \%$ higher than in those cultured on the FGF2-immobilised substrate (64.1\%). Fucosylation level expressed by hMSCs cultured on FN-coated substrate $(84.7 \%)$ was also slightly higher relative to those cultured on PS-MBP-FGF (78.0\%). On the other hand, the abundance of high-mannose type glycans was lower in hMSCs expended on FN-coated substrate (5.2\%) than those expanded on PS-MBP-FGF (9.8\%). Our results revealed a difference in sialylation in undifferentiated hMSCs that depends on cell adhesion to the ECM.

\section{Analysis of sialylated N-linked glycans}

To confirm sialylated $N$-linked glycans in hMSCs, we performed tandem mass analysis using MALDI-QITTOF MS. Among all sialylated $N$-linked glycans, four sialylated glycans (observed at $\mathrm{m} / \mathrm{z} 2605.4,2966.5,3415.6$ and 3776.6 , respectively) were analysed with relative abundances that were higher in hMSCs expanded on the FN-coated substrate compared to those expanded on PSMBP-FGF. The representative MS/MS spectra are shown in Fig. 9. The mass fragmentation pattern represents the cleavage of the glycosidic linkage in oligosaccharides, which yields B- and Y-type fragment ions, referring to the nomenclature proposed by Domon and Costello (1998). The ion peaks at $m / z 2230.2,2591.3,3040.3$ and 3401.4 were generated from $\mathrm{m} / \mathrm{z} 2605.4,2966.5$, 
A

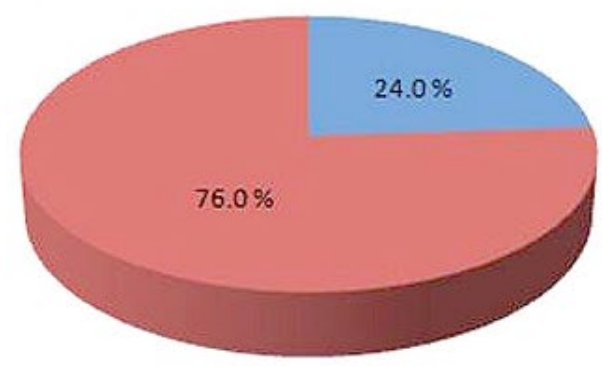

B

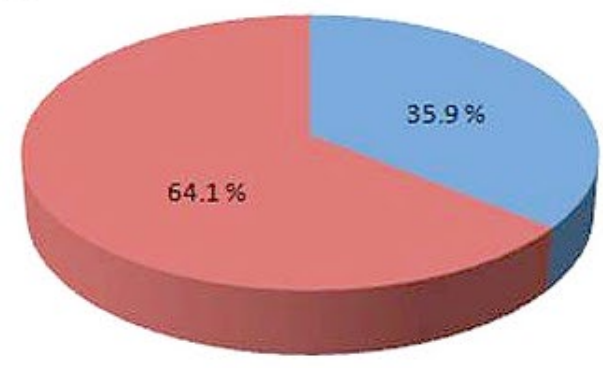

non-sialylated glycan

nialylated glycan
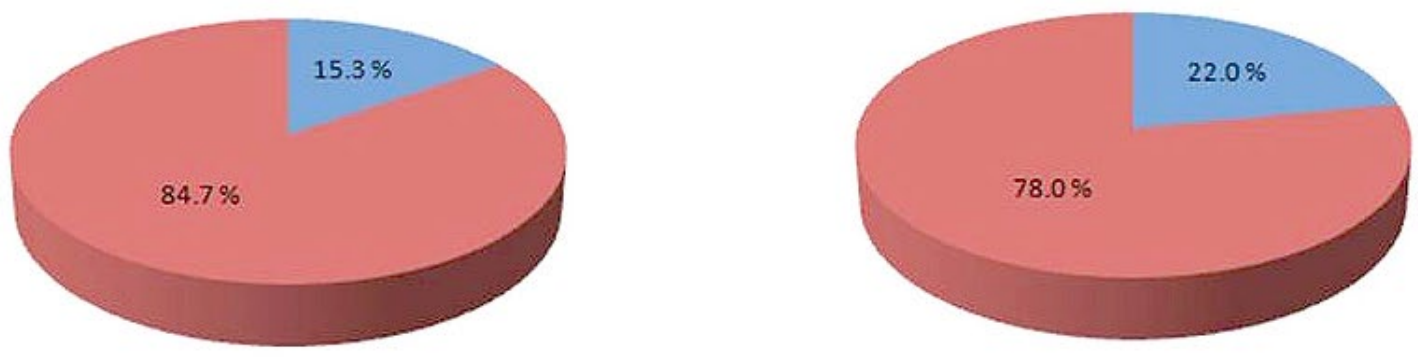

\section{fucosylation}

non-fucosylated glycan

- fucosylated glycan
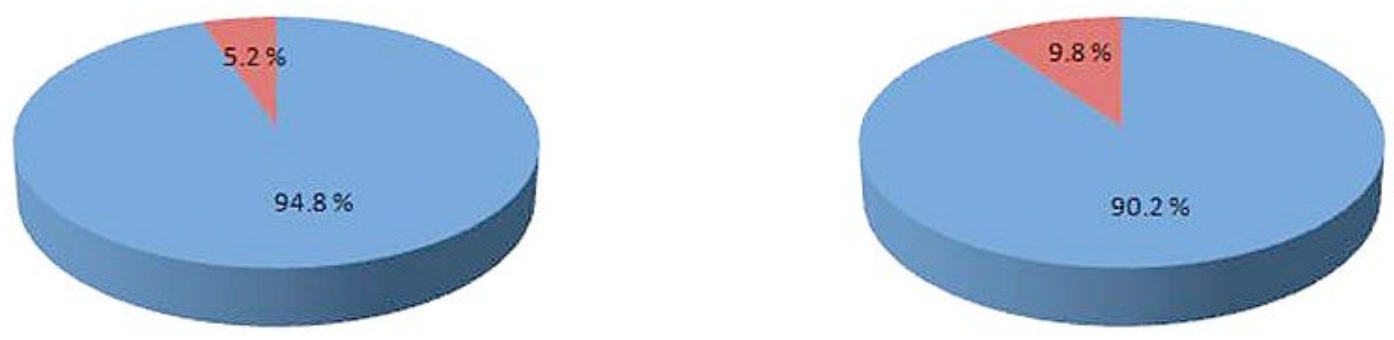

\section{mannosylation}

둘 complex type glycan

- high-mannose type glycan

Fig. 8. Relative quantification of sialylated glycans, fucosylated glycans, and mannosylated glycans from hMSCs expanded on FN-coated substrate (A) and PS-MBP-FGF2 (B). Quantitative analysis was performed by using MALDI-TOF MS instrument combined with solid-phase permethylation. Mass spectra were acquired in the positive ion reflectron mode. The relative quantities of these glycans were estimated from peak intensities of each N-glycan among the intensities of the total N-glycans. The intensity of each peak was obtained by integrating from the first to the third isotopic peak intensities. The experiments were performed in biological duplicate and three technical replicates of each biological entity for reproducibility. 

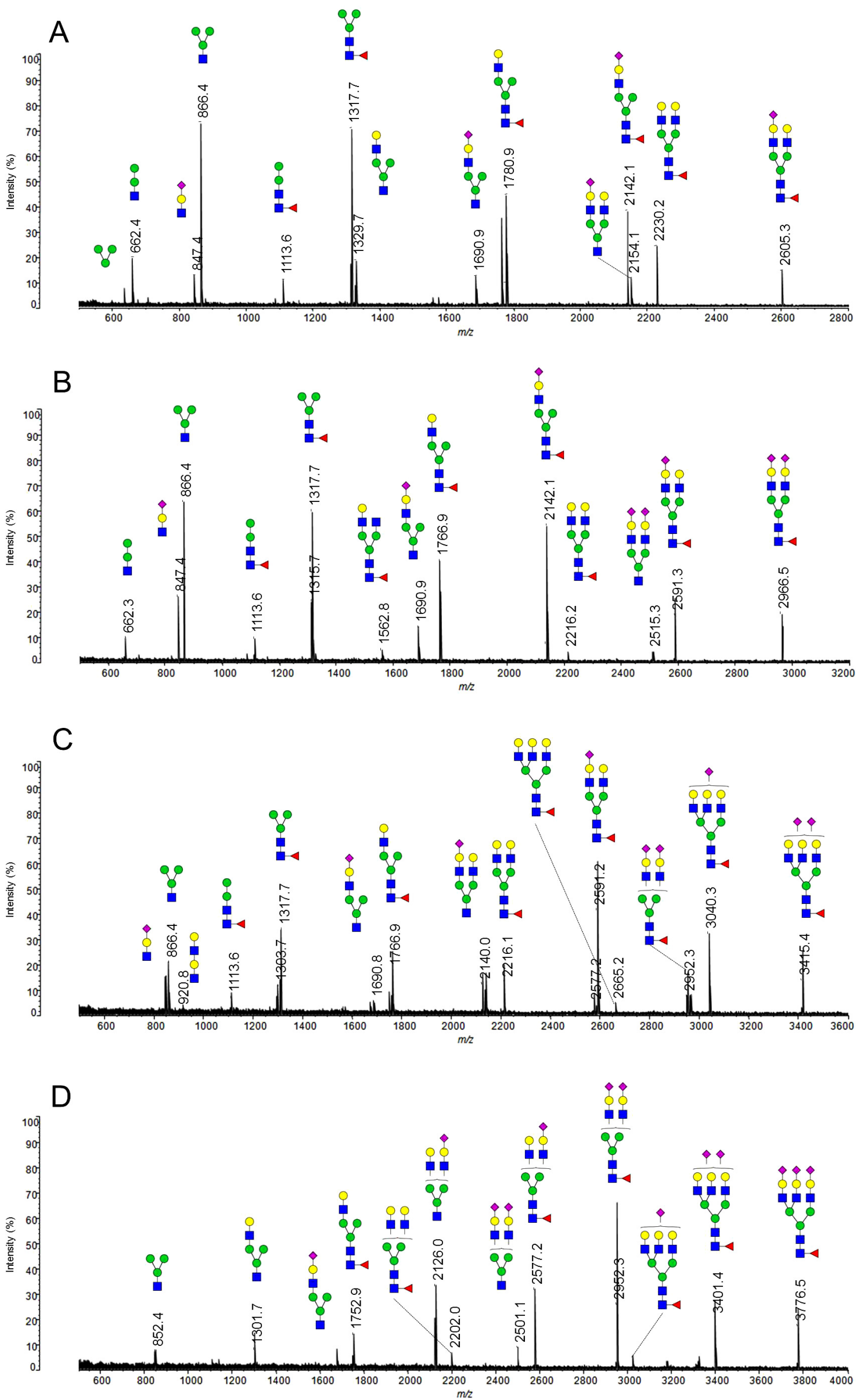

Fig. 9. Confirmation of sialylated glycan structures corresponding to $[\mathrm{M}+\mathrm{Na}]^{+} \mathrm{m} / z$ values of (A) 2605.3 , (B) 2996.5, (C) 3415.4 and (D) 3776.5. 


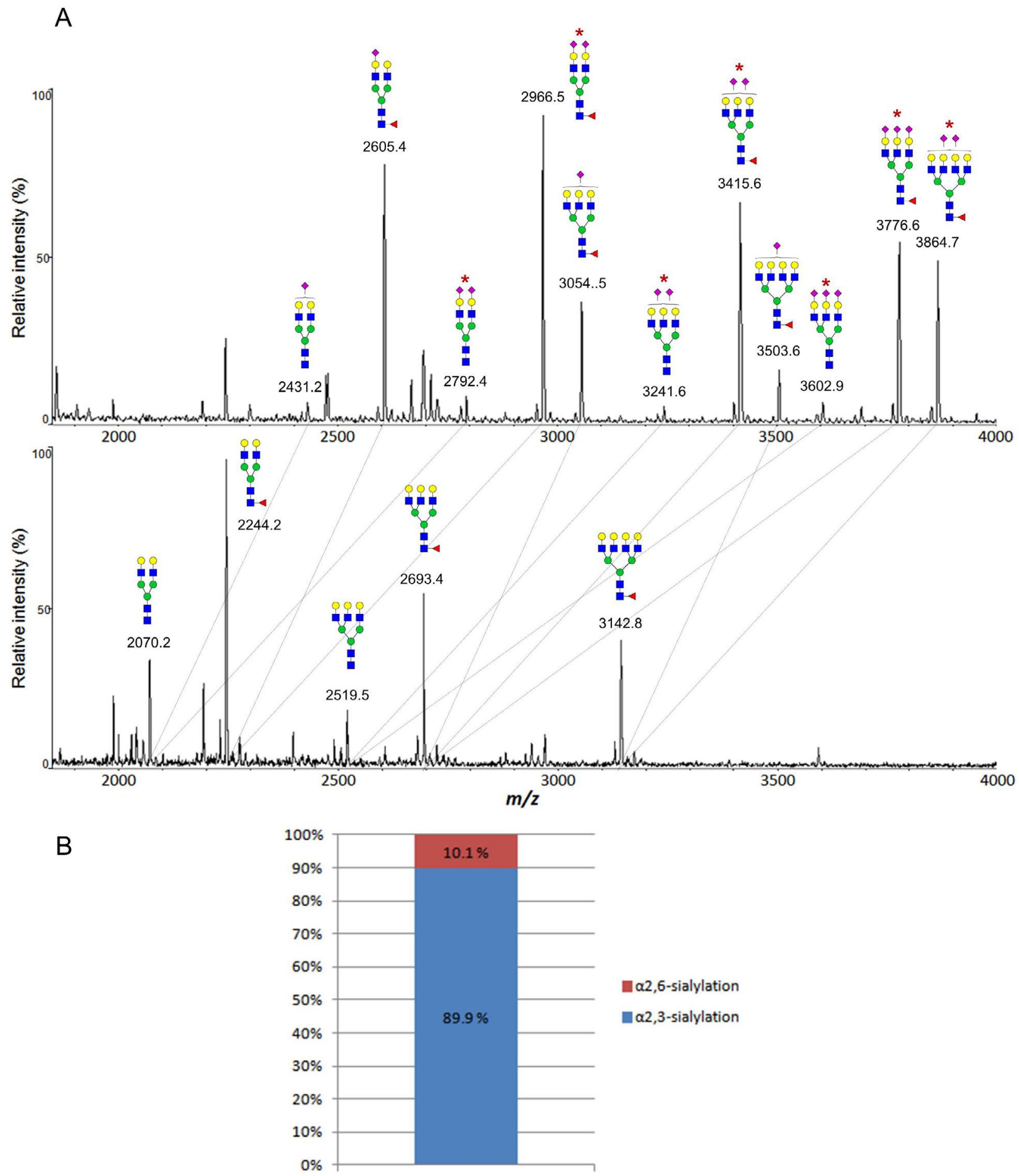

Fig. 10. MALDI-TOF MS analysis. (A) The $N$-linked glycans before and after digestion with $\alpha 2,3$-sialidase; $N$-linked glycans in hMSCs were added to Glyko Sialidase S from Streptococcus pneumoniae (Prozyme, Hayward, CA, USA) and then incubated in $50 \mathrm{mM}$ sodium phosphate buffer ( $\mathrm{pH} 6.0$ ) at $37^{\circ} \mathrm{C}$ for $16 \mathrm{~h}$. MS analysis was performed by using MALDI-TOF MS instrument (Bruker). Mass spectra were acquired in the positive ion reflectron mode. (B) Quantitation of N-glycans with $\alpha 2,3$ - or $\alpha 2,6$-sialylation.

3415.6 and 3776.6 , respectively, by the loss of one sialic acid residue $(-375.2 \mathrm{Da})$. The ion peaks at $\mathrm{m} / \mathrm{z} 2216.2$, 2665.2 and 3026.3 also resulted from $\mathrm{m} / \mathrm{z} 2966.5,3415.6$ and 3776.6 , respectively, by the loss of two sialic acid residues (-750.3 Da). Finally, the ion peak at $m / z 2202.0$ was generated from $m / z 3776.6$ by the loss of a LacNAc and three sialic acid residues. MS/MS analysis revealed that these four $N$-linked glycans are bi-antennary glycans with one and two sialic acids and tri-antennary glycans with two and three sialic acids ( $m / z$ 2605.4, 2966.5, 3415.6 and 3776.6 , respectively). To determine the glycosidic linkage of sialic acids in hMSC $N$-linked glycans, we performed MALDI-TOF MS analysis coupled with $\alpha 2,3-$ sialidase digestion. MS analysis showed that treatment 
with Streptococcus pneumoniae $\alpha 2,3$-sialidase removed or reduced sialic acid residues from complex $N$-linked glycans (Fig. 10). In addition, the ratio of $\alpha 2,3$ - and $\alpha 2,6$ sialylation was determined by relative quantitation using solid-phase permethylation of glycans, and consequently the level of $\alpha 2,3$-sialylated glycans ( $89.9 \%$ of total sialylated glycans) was significantly higher than the that of $\alpha 2,6$-sialylated glycans ( $10.1 \%)$. Thus, $\alpha 2,3$-sialylation of $N$-linked glycans is a predominant feature on the surface of undifferentiated hMSCs and is therefore consistent with previous analysis (Heiskanen et al., 2009).

\section{Discussion}

Polymeric materials or nano/micro-patterned surfaces have been employed as adhesion matrices for stem cell biology studies involving cell morphology and cellular response (Montero-Pancera et al., 2010; Hasirci and Pepe-Mooney, 2012). However, cell adhesion is mediated by non-specific physical interactions. Several studies have been published about adhesion mechanisms that affect cell morphology and adhesion-related signal transduction (Deligianni et al., 2001; Li et al., 2013; Yeung et al., 2005). In the current study, PS-MBP-FGF2 was used as an artificial substrate to control adhesion-mediated signalling and stem cell function through a specific receptor-ligand interaction. We argue that adhesion mechanisms are key to understanding cell adhesion-mediated biology on artificial cell adhesion matrices. We have developed cell adhesion substrates for adult stem cell culture, focusing on a ligand for a nonadhesion cell surface receptor to control cellular responses related to cell adhesion signalling. In our previous study, HSPGs, which are expressed on cell membranes, were selected as non-cell adhesion receptors for controlling integrin signalling (Dalton et al., 1995). We demonstrated that HSPGs mediate the adhesion of hASCs to heparinbinding protein-coated surfaces (Dalton et al., 1995; Kusano et al., 2000). hASC adhesion to an HBD- and FGF2-immobilised surface is strikingly different from adhesion to ECM proteins. For example, heparin inhibits hASCs adhesion to the HBD- and FGF2-immobilised substrates but not cell adhesion to FN. In the current study, we demonstrated that cell adhesion signalling and the cellular response of hMSCs that were expanded on the FGF2-immobilised surface were different from those that were expanded on the FN-coated surface.

Generally, FGF2 transduces its signal through FGFR2. Monitoring FGFR signalling in hMSCs that adhered to PS-MBP-FGF2 was logical. When FGF2 binds to FGFR, the receptor is autophosphorylated, activating the downstream signalling pathway. This in turn activates mitogen-activated protein kinase (MAPK) (Lanner et al., 2010). hMSCs express FGF2 and exhibit FGFR activation within a functional autocrine loop (Rider et al., 2008; Zaragosi et al., 2006). We clarified from western blot analysis and an enzyme-linked immunosorbent assay that FGF2 is expressed by hMSCs and activates MAPK (data not shown). For this reason, we could not determine whether FGFRs were activated by immobilised FGF2 or endogenously expressed FGF2 upon hMSC adhesion.
Alternatively, we showed here that cell adhesion to PSMBP-FGF2 was not inhibited by an FGFR activation inhibitor. We focused on cell adhesion signalling in hMSCs that adhered to surfaces with immobilised FGF2.

FAK is a key molecule involved in the formation of focal contacts at sites of cell-matrix adhesion. In Fig. 3, we showed that FAK phosphorylation was not activated and cytoskeletal reorganisation was restricted in hMSCs that adhered to PS-MBP-FGF2 compared to those that adhered to the FN-coated surface. These data indicate that the HSPG-mediated adhesion of hMSCs to immobilised FGF2 did not initiate integrin signalling.

Integrin signalling is an important factor in the functional regulation of anchorage-dependent cells, such as stem cells, somatic cells and tumour cells. In particular, many reports have shown that integrin signalling regulates stem cell differentiation (Smadja et al., 2014; Yu et al., 2012). These results indicate that control of integrin signalling is valuable for stem cell regulation. To investigate the role of integrins in cell function, antagonist antibodies can be used to inhibit integrin-mediated adhesion. These antagonist antibodies are suitable for a short-term and small-volume culture but not for a longtime and large-volume culture. Matrix engineering based on a specific receptor-ligand interaction, such as has been used in this work, is advantageous for the long term and with a large number of cells to control integrin-mediated cell adhesion. On the other hand, one should use caution because complete inhibition of integrin-mediated adhesion results in apoptosis, termed "anoikis", in anchoragedependent cells (Frisch et al., 2013). During cell adhesion to PS-MBP-FGF2, cell death was not detected with a lactate dehydrogenase assay (data not shown). The cells extended slender processes during culture and proliferated slowly compared to cells that adhered to the FN-coated surface, indicating that integrin-mediated adhesion is partially activated on PS-MBP-FGF2 during culture. In general, cells express ECM proteins (such as fibronectin, collagen and laminin) and regulate their microenvironments during culture. hMSCs could express ECM proteins on PSMBP-FGF2 after being attached to the substrate through FGF2-HSPG interaction and the partial integrin activation might be caused by these expressed ECM proteins. The initial restriction of integrin-mediated adhesion by PSMBP-FGF2 is useful to address hMSC behaviour under the restricted condition of integrin signalling, although integrin signalling is partially activated on the substrate during culture, because cells cannot survive and proliferate under complete inhibition of integrin-mediated adhesion.

Most studies have focused on differentiation of adult stem cells into specific cells, such as chondrogenic, osteogenic and adipogenic cells, after attachment to adhesion matrices. In the current study, we sought to characterise hMSC behaviour, such as their phenotype and differentiation properties, of cells that were expanded in the presence of integrin-mediated adhesion and integrin-restricted adhesion. MSCs have been described as expressing the surface markers CD29, CD90, CD105 and CD166, and these markers are also expressed in endothelial, epithelial and muscle cells (De Schauwera et al., 2011). In the current study, the number of cells 
expressing these surface markers was not different when cells were grown on PS-MBP-FGF2 or the FN-coated surface. However, the intensity of expression of these surface markers on the cells appeared different between the two culture conditions. These results indicated that although cells express the surface markers, the level of expression may be critical for classification of MSCs. Taken together these results show that integrin restricted adhesion (i.e. adhesion through HSPG) results in lower MSC marker intensity and reduction in differentiation potential, highlighting the importance of integrin adhesion for maintaining stem cell multipotency. Therefore, the characterisation of biomaterial surface properties on cell adhesion is necessary in order to understand how MSC differentiation will be affected.

Recently, glycomics has received attention with regards to the characterisation of MSC and embryonic stem cell phenotype. Here we addressed the relationship between the glycan profile and the fate of MSCs as determined by their cell adhesion mechanism. MS-based quantitative analysis of stem cell surface $N$-linked glycans was performed using solid-phase permethylation, which is stable with respect to the peeling reaction and oxidative degradation of the sialic acids. Quantitative analysis showed that sialylated $N$-linked glycans are abundant in both hMSCs cultured on the FGF2-immobilised substrate and those cultured on the FN-coated substrate. Recently, Heiskanen et al. (2009) and Hamouda et al. (2013) demonstrated the differences in $\mathrm{N}$-glycomes in both undifferentiated and differentiated MSCs (adipogenically and osteogenically, respectively). However, no previous reports have described the difference in $\mathrm{N}$-glycomes in terms of the phenotype and differentiation potential of hMSCs in association with the cell adhesion mechanism. Therefore, to the best of our knowledge, this is the first comparative profiling of $N$-linked glycans from undifferentiated hMSCs according to the cell adhesion mechanism for differentiation potential control.

A previous study demonstrated that sialylated glycans expressed on the surface of stem cells is essential for differentiation of stem cells into specific cells (Takahata et al., 2007). Furthermore, the ratio of sialylation level by the specific linkage of sialic acid in glycoconjugates has been reported to be dependent on differentiation of stem cells (Takahata et al., 2007; Wolosin and Wang, 1995). In the current study, $\alpha 2,3$-sialylated glycans from hMSCs were identified by exoglycosidase digestion and quantified with solid-phase permethylation. A previous study reported that induced pluripotent stem cells (iPSCs) have more $\alpha 2,6$-sialylation than $\alpha 2,3$-sialylation (Hasehira et al., 2012), suggesting that MSCs may have different sialylation from other stem cell species. Although the biological roles of $\alpha 2,3$-sialylation in stem cells remain largely unknown, previous studies have demonstrated that $\alpha 2,3$-sialylation may regulate cellular mechanisms, such as cell adhesion and differentiation. $\alpha 2,3$-sialylation of the CD44 protein, which is a ubiquitous cell membrane protein, allows MSC trafficking to bone by the binding of carbohydrate receptors, such as E-selectin (Sackstein et al., 2008). $\alpha 2,3$-sialylation also regulates the stability of the CD133 protein, which is widely used as a marker for the isolation of normal and cancer stem cells (Zhou et al., 2010), suggesting that the glycosylation of CD133 may be associated with cell differentiation. In addition, the distribution of $\alpha 2,3$ - and $\alpha 2,6$-sialylation on the stem cell surface affects differentiation (Takahata et al., 2007; Wolosin and Wang, 1995).

\section{Conclusions}

In conclusion, elucidating the events that take place at surfaces or interfaces of biological systems is important for improving the design of highly functional biomaterials. On FGF2-immobilised surfaces, HSPG-mediated cell adhesion was independent from integrin signalling, although adhesion processes that occur at the interface between HSPG surfaces and hMSCs remain to be examined further. Glycomics analysis showed that $\alpha 2,3$-sialylation may be intimately related to hMSC function. Adhesion mechanisms were found to be important in controlling MSC multipotency, with integrin-independent adhesion resulting in a decrease in multipotency compared to integrin-mediated adhesion. This work highlights the importance of biological surfaces on cell adhesion mechanisms and glycobiology, especially in terms of applications for MSCs and biomaterials in regenerative medicine.

\section{Acknowledgements}

We thank I.S. Park for assistance with immunofluorescence staining. This study was supported through the National Research Foundation grant (NRF-2006-2004339), Korea Basic Science Institute grant (T34617), and Korea Institute of Science and Technology grant (2Z04090) funded by the Korea government. We wish to confirm that there are no known conflicts of interest associated with this publication and there has been no significant financial support for this work that could have influenced its outcome.

\section{References}

Adewumi O, Aflatoonian B, Ahrlund-Richter L, Amit M, Andrews PW, Beighton G, Bello PA, Benvenisty N, Berry LS, Bevan S, Blum B, Brooking J, Chen KG, Choo ABH, Churchill GA, Churchill M, Damjanov I, Draper JS, Dvorak P, Emanuelsson K, Fleck RA, Ford A, Gertow K, Gertsenstein M, Gokhale PJ, Hamilton RS, Hampl A, Healy LE, Hovatta O, Hyllner J, Imreh MP, ItskovitzEldor J, Jackson J, Johnson JL, Jones M, Kee K, King BL, Knowles BB, Knowles M, Lebrin F, Mallon BS, Manning D, Mayshar Y, Mckay RDG, Michalska AE, Mikkola M, Mileikovsky M, Minger SL, Moore HD, Mummery CL, Nagy A, Nakatsuji N, O’Brien CM, Oh SKW, Pedersen R, Pera MF, Piekarczyk MS, Pera RAR, Reubinof BE, Robins AJ, Rossant J, Rugg-Gunn P, Schulz TC, Semb H, Sherrer ES, Siemen H, Stacey GN, Stojkovic M, Suemori H, Szatkiewicz J, Turetsky T, Tuuri T, Brink SVD, Vintersten K, Vuoristo S, Ward D, Weaver TA, Young LA, Zhang W (2007) Characterization of human embryonic 
stem cell lines by the international stem cell initiative. Nat Biotechnol 25: 803-816.

An HJ, Gip P, Kim J, Wu S, Park KW, McVaugh CT, Schaffer DV, Bertozzi CR, Lebrilla CB (2012) Extensive determination of glycan heterogeneity reveals an unusual abundance of high mannose glycans in enriched plasma membranes of human embryonic stem cells. Mol Cell Proteomics 11: M111 010660.

Ayala R, Zhang C, Yang D, Hwang Y, Aung A, Shroff SS, Arce FT, Lal R, Arya G, Varghese S (2011) Engineering the cell-material interface for controlling stem cell adhesion, migration, and differentiation. Biomaterials 32: 3700-3711.

Bianco P, Riminucci M, Gronthos S, Robey PG (2012) Bone marrow stromal stem cells: nature, biology, and potential applications. Stem Cell 19: 180-192.

Brammer KS, Choi C, Frandsen CJ, Oh S, Jin S (2011) Hydrophobic nanopillars initiate mesenchymal stem cell aggregation and osteo-differentiation. Acta Biomater 7: 683-690.

Carvalho AM, Alves ALG, Golim MA, Moroz A, Hussania CA, Oliveira PGG, Deffune E (2009) Isolation and immunophenotypic characterization of mesenchymal stem cells derived from equine species adipose tissue. Vet Immunol Immunopathol 132: 303-306.

Chamberlain G, Fox J, Ashton B, Middleton J (2007) Mesenchymal stem cells: their phenotype, differentiation capacity, immunological features, and potential for homing. Stem Cell 25: 2739-2749.

Conget PA, Minguell JJ (1999) Phenotypical and functional properties of human bone marrow mesenchymal progenitor cells. J Cell Physiol 181: 67-73.

Curran JM, Chen R, Hunt JA (2005) Controlling the phenotype and function of mesenchymal stem cells in vitro by adhesion to silane-modified clean glass surfaces. Biomaterials 26: 7057-7067.

Dalton BA, McFarland CD, Underwood PA and Steele JG (1995) Role of the heparin binding domain of fibronectin in attachment and spreading of human bonederived cells. J Cell Sci 108: 2083-2092.

DeligianniDD, Katsalaa ND, Koutsoukosb PG, Missirlisa YF (2001) Effect of surface roughness of hydroxyapatite on human bone marrow cell adhesion, proliferation, differentiation and detachment strength. Biomaterials 22: 87-96.

De Schauwera C, Meyerb E, Van de Wallec GR, Van Soom A(2011) Markers of stemness in equine mesenchymal stem cells: a plea for uniformity. Theriogenology 75: 1431 1443.

Domon B, Costello CE (1998) A systematic nomenclature for carbohydrate fragmentations in Fab-Ms Ms spectra of glycoconjugates. Glycoconj J 5: 397-409.

Engler AJ, Sen S, Sweeney HL, Discher D (2006) Matrix elasticity directs stem cell lineage specification. Cell 126: 677-689.

Frisch SM, Schaller M, Cieply B (2013) Mechanisms that link the oncogenic epithelial-mesenchymal transition to suppression of anoikis. J Cell Sci 126: 21-29.

Giancotti FG, Ruoslahti E (1999) Integrin signaling. Science 285: 1028-1032.
Guilak F, Cohen DM, Estes BT, Gimble JM, Liedtke W, Chen CS (2009) Control of stem cell fate by physical interactions with the extracellular matrix. Cell Stem Cell 5: 17-26.

Hamouda H, Ullah M, Berger M, Sittinger M, Tauber R, Ringe J, Blanchard V (2013) N-Glycosylation profile of undifferentiated and adipogenically differentiated human bone marrow mesenchymal stem cells: towards a next generation of stem cell markers. Stem Cell Dev 22: 31003113.

Han M, Park I-S, Kim SH, Kim BS, Kim S-H (2009) Design and characterization of a maltose binding proteinlinked growth factor for matrix engineering. Biotechnol Lett 31: 1677-1684.

Hasehira K, Tateno H, Onuma Y, Ito Y, Asashima M, Hirabayashi J (2012) Structural and quantitative evidence for dynamic glycome shift on production of induced pluripotent stem cells. Mol Cell Proteomics 11: 1913-1923.

Hasirci V, Pepe-Mooney BJ (2012) Understanding the cell behavior on nano-/micro-patterned surfaces. Nanomedicine 7: 1375-1389.

Heiskanen A, Hirvonen T, Salo H, Impola U, Olonen A, Laitinen A, Tiitinen S, Natunen S, Tiitinen S, Natunen S, Aitio O, Miller-Podraza H, Wuhrer M, Deelder AM, Natunen J, Laine J, Lehenkari P, Saarinen J, Satomaa T, Valmu L (2009) Glycomics of bone marrow-derived mesenchymal stem cells can be used to evaluate their cellular differentiation stage. Glycoconj J 26: 367-384.

Hemmoranta H, Satomaa T, Blomqvist M, Heiskanen A, Aitio O, Saarinen J, Natunen J, Partanen J, Laine J, Jaatinen T (2007) N-glycan structures and associated gene expression reflect the characteristic $\mathrm{N}$-glycosylation pattern of human hematopoietic stem and progenitor cells. Exp Hematol 35: 1279-1292.

Kang P, Mechref Y, Novotny MV (2008) Highthroughput solid-phase permethylation of glycans prior to mass spectrometry. Rapid Commun Mass Spectrom 22: 721-734.

Kang JM, Han M, Park IS, Jung Y, Kim SH, Kim SH (2012) Adhesion and differentiation of adipose-derived stem cells on a substrate with immobilized fibroblast growth factor. Acta Biomater 8: 1759-1767.

Kim S-H, Goto M, Akaike T (2001) Specific binding of glucose-derivatized polymers to the asialoglycoprotein receptor of mouse primary hepatocytes. J Biol Chem 276: 35312-35319.

Kim S-H, Hoshiba T, Akaike T (2004) Hepatocyte behavior on synthetic glycopolymer matrix: inhibitory effect of receptor-ligand binding on hepatocytes spreading. Biomaterials 25: 1813-1823.

Kim S-H, Park I-S, Han M, Rhie J-W, Kim SH, Jung YM, Kim SH (2009) The correlation between human adipose-derived stem cells differentiation and cell adhesion mechanism. Biomaterials 30: 6835-6843.

Ktari N, Poncet P, Sénéchal H, Malaquin L, Kanoufi F, Combellas C (2010) Patterning of polystyrene by scanning electrochemical microscopy. biological applications to cell adhesion. Langmuir 26: 17348-17356.

Kusano Y, Oguri K, Nagayasu Y, Munesue S, Ishihara M, Saiki I, Yonekura H, Yamamoto H, Okayama M (2000) 
Participation of syndecan 2 in the induction of stress fiber formation in cooperation with integrin alpha5beta1: structural characteristics of heparan sulfate chains with avidity to $\mathrm{COOH}$-terminal heparin-binding domain of fibronectin. Exp Cell Res 256: 434-444.

Lanctot PM, Gage FH, Varki AP (2007) The glycans of stem cells. Curr Opin Chem Biol 11: 373-380.

Lanner F, Lee KL, Sohl M, Holmborn K, Yang H, Wilbertz J, Poellinger L, Rossant J, Farnebo F (2010) Heparan sulfation-dependent FGF signaling maintains embryonic stem cells primed for differentiation in a heterogeneous state. Stem Cell 28: 192-200.

Li H, Frith J, Cooper-White JJ (2013) Modulation of stem cell adhesion and morphology via facile control over surface presentation of cell adhesion molecules. Biomacromolecules 15: 43-52.

McBeath R, Pirone DM, Nelson CM, Bhadriraju K, Chen CS (2004) Cell shape, cytoskeletal tension, and Rho A regulate stem cell lineage commitment. Dev Cell 4: 483495.

McMurray RJ, Gadegaard N, Tsimbouri PM, Burgess KV, McNamara LE, Tare R, Murawski K, Kingham E, Oreffo ROC, Dalby MJ (2011) Nanoscale surfaces for the long-term maintenance of mesenchymal stem cell phenotype and multipotency. Nat Mater 10: 637-644.

Montero-Pancera S, Trouillet V, Petershans A, Fichtner D, Lyapin A, Bruns M, Schimmel T, Wedlich D, Reichlmaier S, Weidler PG, Gliemann H (2010) Design of chemically activated polymer microwells by one-step UV-lithography for stem cell adhesion. Langmuir 26: 2050-2056.

Muramatsu T, Muramatsu H (2004) Carbohydrate antigens expressed on stem cells and early embryonic cells. Glycoconj J 21: 41-45.

Rider DA, Dombrowski C, Sawyer AA, Ng GH, Leong D, Hutmacher DW, Nurcombe V, Cool SM (2008) Autocrine fibroblast growth factor 2 increases the multipotentiality of human adipose-derived mesenchymal stem cells. Stem Cell 26: 1598-1608.

Ross JA, Ansell I, Hjelle JT, Anderson JD, Miller-Hjelle MA, Dobbie JW (1998) Phenotypic mapping of human mesothelial cells. Adv Perit Dial 14: 25-30.

Sackstein R, Merzaban JS, Cain DW, Dagia NM, Spencer JA, Lin CP, Wohlgemuth R (2008) Ex vivo glycan engineering of CD44 programs human multipotent mesenchymal stromal cell trafficking to bone. Nat Med 14: 181-187.

Satomaa T, Heiskanen A, Mikkola M, Olsson C, Blomqvist M, Tiittanen M, Jaatinen T, Aitio O, Olonen A, Olonen J, Hiltunen J, Natune J, Tuuri T, Otonkoski T, Saarinen J, Laine J (2009) The N-glycome of human embryonic stem cells. BMC Cell Biol 10: 42-60.

Schaller MD, Hildebrand JD, Shannon JD, Fox JW, Vines RR, Parsons JT (1994) Autophosphorylation of the focal adhesion kinase, pp125FAK, directs SH2-dependent binding of pp60src. Mol Cell Biol 14: 1680-1688.

Schopperle WM, DeWolf WC (2007) The TRA-1-60 and TRA-1-81 human pluripotent stem cell markers are expressed on podocalyxin in embryonal carcinoma. Stem Cell 25: 723-730.

Smadja DM, Guerin CL, Boscolo E, Bieche I, Mulliken JB, Bischoff J (2014) $\alpha 6$-Integrin is required for the adhesion and vasculogenic potential of hemangioma stem cells. Stem Cell 32: 684-693.

Takahata M, Iwasaki N, Nakagawa H, Abe Y, Watanabe T, Ito M, Majima T, Minami A (2007) Sialylation of cell surface glycoconjugates is essential for osteoclastogenesis. Bone 41: 77-86.

Wearne KA, Winter HC, O’Shea K, Goldstein IJ (2006) Use of lectins for probing differentiated human embryonic stem cells for carbohydrates. Glycobiology 16: 981-990.

Wexler SA, Donaldson C, Denning-Kendall P, Rice C, Bradley B, Hows JM (2013) Adult bone marrow is a rich source of human mesenchymal 'stem' cells but umbilical cord and mobilized adult blood are not. Br J Haematol 121: 368-374.

Wolosin JM, Wang Y (1995) Alpha-2,3 sialylation differentiate the limbal and corneal epithelial cell phenotypes. Invest Ophthalmol Vis Sci 36: 2277-2286.

Yeung T, Georges PC, Flanagan LA, Marg B, Ortiz M, Funaki M, Zahir N, Ming W, Weaver V, Janmey PA (2005) Effects of substrate stiffness on cell morphology, cytoskeletal structure, and adhesion. Cell Motil Cytoskeleton 60: 24-34.

Yu KR, Yang SR, Jung JW, Kim H, Ko K, Han DW, Park SB, Choi SW, Kang SK, Schöler H, Kang KS (2012) CD49f enhances multipotency and maintains stemness through the direct regulation of OCT4 and SOX2. Stem Cell 30: 876-887.

Zaragosi LE, Ailhaud G, Dani C (2006) Autocrine fibroblast growth factor 2 signaling is critical for selfrenewal of human multipotent adipose-derived stem cells. Stem Cell 24: 2412-2419.

Zhou F, Cui C, Ge Y, Chen H, Li Q, Yang Z, Wu C, Sun S, Chen K, Gu J, Jiang J, Wei Y (2010) Alpha2,3Sialylation regulates the stability of stem cell marker CD133. J Biochem 148: 273-280.

\section{Discussion with Reviewer}

Reviewer I: The differentiation potential of hMSCs on a PS surface with immobilised FGF2 is clearly decreased, and the proliferation rate is also decreased. It is interesting to know whether these stem cells still keep their differentiation potential when cultured on a normal surface.

Authors: hMSCs kept their adipogenic and osteogenic potential when cultured on tissue culture plastic dishes (a normal surface). 